\title{
On the Importance of a Consistent Treatment of Prognostic Moisture Variables between Convective and Microphysical Parameterizations
}

\author{
EVELYN D. GRELL \\ Cooperative Institute for Research in Environmental Sciences, University of Colorado Boulder, \\ and NOAA/Earth System Research Laboratory, Boulder, Colorado \\ JIAN-WEN BAO \\ NOAA/Earth System Research Laboratory, Boulder, Colorado
}

DAVID E. KINGSMILL

Cooperative Institute for Research in Environmental Sciences, University of Colorado Boulder, Boulder, Colorado

SARA A. MichELSON

Cooperative Institute for Research in Environmental Sciences, University of Colorado Boulder, and NOAA/Earth System Research Laboratory, Boulder, Colorado

(Manuscript received 18 October 2017, in final form 7 February 2018)

\begin{abstract}
Analysis of WRF Model output from experiments using two double-moment microphysics schemes is carried out to demonstrate that there can be an inconsistency between the predicted mass and number concentrations when a single-moment convective parameterization is used together with a double-moment microphysics scheme. This inconsistency may arise because the grid-scale and subgrid-scale cloud schemes generally apply different levels of complexity to the parameterized microphysical processes. In particular, when a multimoment formulation is used in the microphysics scheme and other physical parameterizations modify only the mass-related moment while the values of the second (or higher) moment for individual hydrometeors remain unchanged, an unintended modification of the particle size distribution occurs. Simulated radar reflectivity is shown to be a valuable tool in diagnosing this inconsistency. In addition, potential ways to minimize the problem are explored by including number concentration calculations in the cumulus parameterization that are consistent with the assumptions of hydrometeor sizes in the microphysics parameterization. The results of this study indicate that it is physically preferable to unify microphysical assumptions between the grid-resolved and subgrid cloud parameterization schemes in weather and climate simulation models.
\end{abstract}

\section{Introduction}

In mesoscale numerical weather prediction (NWP) models, precipitating clouds are generally described through implementation of microphysical and convective parameterizations. Microphysical parameterizations (MPs) describe the specific subgrid-scale processes that form cloud and precipitation particles, as well as their interactions; convective parameterizations (CPs) compute heat and moisture changes caused by unresolved processes, and produce precipitation when

Corresponding author: Evelyn D. Grell, evelyn.grell@noaa.gov such changes result in condensation. The well-posed interaction of these parameterizations is critical for accurate precipitation forecasts.

The basic goal of parameterizing convection is to determine the impact of subgrid clouds on the larger-scale model environment. Many different approaches exist to determine where convection will develop and how it will feed back to the environment (e.g., Frank 1983; Grell et al. 1991; Emanuel and Raymond 1993; Emanuel 1994; Arakawa 2004). One common category of CP is the mass-flux scheme, in which the environmental temperature and humidity profiles are adjusted to account for parameterized convective feedback through lateral 
mixing, and for compensating subsidence induced by the flux of mass in the convective updraft. When condensate forms in the updraft, a fraction of it is removed as convective precipitation, with the remainder detrained into the environment as cloud water or ice. The MP then determines any further response to the detrained hydrometeors. Convective detrainment is one of the primary processes through which subgrid convection affects the grid-scale environment. As an important water source for anvil clouds, for example, the detrainment of cloud water and ice from convection can strongly influence the formation of precipitation within the microphysics scheme.

Grid-scale cloud processes are represented by the microphysics parameterization. Within the MP, cloud and precipitation particles are formed and modified, according to the parameterization assumptions and simulated environmental conditions. Most schemes include equations for processes such as nucleation, autoconversion (the growth of droplets from cloud particles to precipitating particles), collision and coalescence between hydrometeors, melting, freezing, and sedimentation (fallout).

The microphysics schemes used in NWP models vary widely in complexity. They differ in the number of prognostic parameters used to describe hydrometeors, as well as in the assumptions used to describe the microphysical processes. In the commonly used bulk microphysics schemes, the distribution of each hydrometeor species is represented by a prescribed size spectrum (e.g., exponential, gamma, etc.). In single-moment schemes, only one property of the hydrometeor species is predicted, typically the mass mixing ratio, and other characteristics, or moments, are based upon prescribed particle size distribution assumptions. In double-moment schemes, separate prognostic equations are included for two characteristics of the particle size distribution, most often the total number concentration and the mass mixing ratio for a set of hydrometeor species such as cloud liquid, cloud ice, snow, rain, graupel, and hail.

The use of double-moment bulk MPs (e.g., Milbrandt and Yau 2005; Morrison et al. 2005; Thompson et al. 2008; Seifert and Beheng 2006; Lim and Hong 2010) provides a priori advantages over single-moment schemes (Reisner et al. 1998; Seifert and Beheng 2006). They can greatly improve the representation of size distributions and hence microphysical processes and cloud-radiative interaction by allowing the particle mass and number to vary independently (Dawson et al. 2010; Milbrandt and Yau 2005, 2006; Morrison et al. 2005, 2009; Klein et al. 2009). When coupled to an appropriate aerosol activation parameterization, double-moment schemes are capable of modeling the modification of cloud properties by aerosol emissions, a key component of anthropogenic climate change (IPCC 2007; Lohmann and Feichter 2005; Kaufman and Koren 2006). In addition, particle fall speeds may vary based on size, rather than imposing a single mean fall speed as in a onemoment scheme (Milbrandt and Yau 2005).

Hydrometeor mass and number concentration are not, however, completely independent variables. Differential sedimentation of mass and number can lead to excessive size sorting (Cohard and Pinty 2000; Milbrandt and Yau 2005). Another potential issue with double-moment MPs is that other model components, most notably the $\mathrm{CP}$, may impact one moment of a given species but not the other. For example, a CP may detrain cloud water, changing the cloud water mixing ratio. Typically, it does not contribute to any change to the cloud water number concentration, and as a result, the distribution of drop sizes for the species is altered. Unless accounted for, this could lead to an inconsistency in the moments, or at the very minimum, degrade the value of computing the second moment.

Accounting for the contribution from the $\mathrm{CP}$ remains a subject of research. In the Morrison MP in the Weather Research and Forecasting (WRF) Model (Morrison et al. 2009), moisture tendencies from the CP are input to the MP and number concentrations are computed corresponding to these mixing ratio tendencies, using an assumed size distribution. In other work (Arakawa et al. 2011; Arakawa and Wu 2013; Gerard 2015, among others), the approach of "unified parameterization" is proposed, in which resolved and unresolved cloud processes are addressed within a single scheme.

The objective of the research presented in this paper is to explore the cause and effect of various cloud microphysical feedbacks through budget analysis and sensitivity experiments, and demonstrate the importance of microphysical consistency between subgrid and resolved cloud parameterizations when applied in the Advanced Research WRF (WRF-ARW) Model (Skamarock et al. 2008). Comparison of observed and simulated reflectivity is shown to be a useful tool in diagnosing mass-number consistency for precipitating hydrometeors.

\section{The case study and observations}

The simulated case covers the 36 -h period from 0600 UTC 15 February to 1800 UTC 16 February 2011, during which time a winter storm made landfall on the coast of California. This system was the second of two atmospheric river (AR) events to impact the California coast in a 3-day period. Although weaker than the first AR, it was characterized by a band of enhanced vertically integrated water vapor, which approached the coast from the west-northwest. This AR was associated with a large 
region of cyclonic circulation situated over the Gulf of Alaska, which migrated southeastward during 14-16 February. The meteorological situation is described in more detail by Kingsmill et al. (2013).

Some observations from this event are available as part of the National Oceanic and Atmospheric Administration's Hydrometeorology Testbed (HMT; Ralph et al. 2005, 2013). Surface observations of temperature, relative humidity, pressure, winds, and rainfall are available at multiple locations within the model domain. An S-band $(3 \mathrm{GHz}$ ) precipitation profiler (White et al. 2000) deployed at Cazadero, California, provided vertical profiles of reflectivity at high temporal and spatial resolution.

The rainfall in this region has been extensively studied since 1998 using data from the California Land-falling Jets (CALJET), Pacific Land-falling Jets (PACJET), and HMT experiments (Ralph et al. 2005, 2013). Numerous investigations (e.g., White et al. 2003, 2015; Neiman et al. 2005; Kingsmill et al. 2006, 2016; Martner et al. 2008) have documented two relatively distinct microphysics regimes: one associated with the seeder-feeder process where ice particles aloft play a large role in precipitation development, and the other associated with a shallow warm-rain (i.e., collision-coalescence) process where ice particles aloft play at most a minor role in precipitation development. Orographic processes were found to have a marked effect on the raindrop size spectra.

\section{Model and experiments}

The model domain is shown in Fig. 1. Simulations were performed using the WRF-ARW Model, version 3.6, on a grid consisting of $383 \times 349$ grid points with 59 vertical layers and a horizontal resolution of $4 \mathrm{~km}$. Model output was written at 15-min intervals for the entire 36-h simulation, to provide a relatively highfrequency time evolution of the event. The initial and lateral boundary conditions were derived from the North American Mesoscale Forecast System (NAM) analyses, and the model physics options used for all simulations include the following: RRTM longwave radiation (Mlawer et al. 1997), Dudhia (1989) shortwave radiation, a MoninObukhov surface parameterization, the unified Noah land surface model (Tewari et al. 2004), and the Mellor-Yamada-Janjić (Janjić 1994) boundary layer parameterization. Microphysical and convective parameterizations were varied, as described below. Besides the microphysics and convection schemes, there is no additional subgrid condensation scheme. A summary of the initial experiments for this case is listed in Table 1; additional experiments are described in the results section.

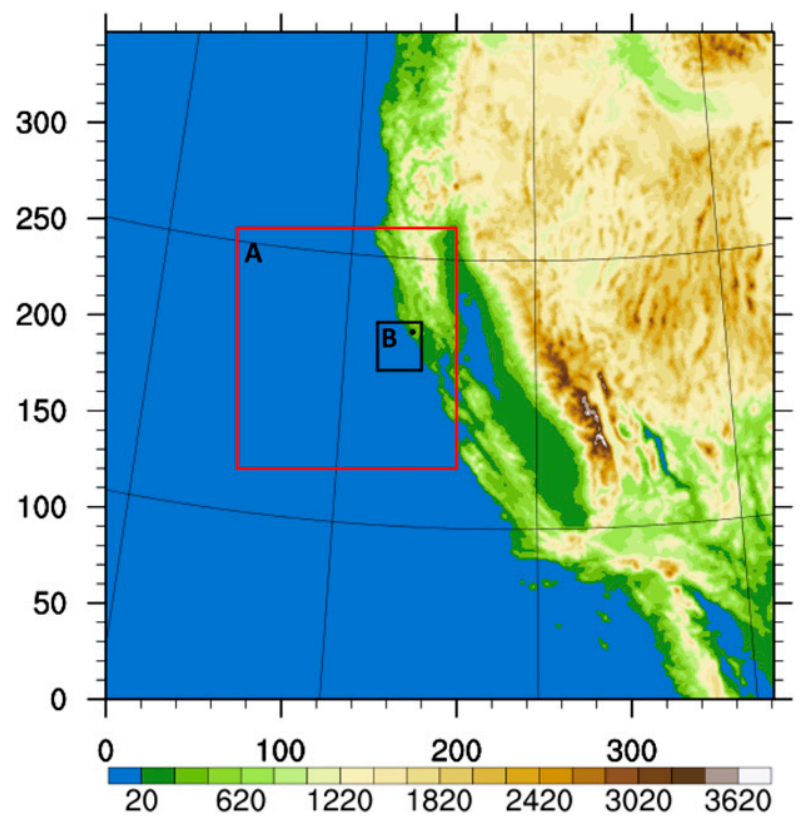

FIG. 1. Model domain, with terrain heights in color. The two boxes are subdomains referenced within the text, and the black dot is the location of station CZC (Cazadero, CA).

For the microphysics parameterization, either the Thompson (Thompson et al. 2008) or Morrison (Morrison et al. 2009) scheme was used. Both of these schemes have prognostic equations for the mixing ratio tendencies of cloud water, rain, ice, snow, and graupel. In addition, both compute a second moment (number concentration) for some hydrometeor species. In the Thompson scheme, rain and ice have two prognostic moments, while the Morrison scheme additionally predicts two moments for snow and graupel. The number of cloud droplets is prescribed in both schemes (see Tables 2, 3).

For subgrid convection, experiments used either no cumulus parameterization (NoCP), the Kain-Fritsch (KF) scheme (Kain 2004), or the "scale-aware" GrellFreitas (GF; Grell and Freitas 2014) parameterization. Both CPs are mass-flux schemes, with entraining updrafts and downdrafts that transfer heat and moisture within a vertical column. A shallow convection component was included for both schemes. The GF scheme computes changes in water vapor, cloud water, ice, and temperature. The KF scheme additionally produces tendencies for rain and snow. A multiscale version of the $\mathrm{KF}$ parameterization was also tested.

\section{Model simulation results}

\section{a. Precipitation patterns at $12 \mathrm{~h}$}

The low-level winds and total accumulated precipitation at $12 \mathrm{~h}$ for the $500 \mathrm{~km} \times 500 \mathrm{~km}$ subdomain 
TABLE 1. Experiments.

\begin{tabular}{lcc}
\hline $\begin{array}{c}\text { Experiment } \\
\text { name }\end{array}$ & $\begin{array}{c}\text { Microphysics } \\
\text { parameterization }\end{array}$ & $\begin{array}{c}\text { Convection } \\
\text { parameterization }\end{array}$ \\
\hline Thom-NoCP & Thompson & None \\
Thom-KF & Thompson & Kain-Fritsch \\
Thom-GF & Thompson & Grell-Freitas \\
Morr-NoCP & Morrison & None \\
Morr-KF & Morrison & Kain-Fritsch \\
Morr-GF & Morrison & Grell-Freitas \\
\hline
\end{tabular}

called box A (refer to Fig. 1) shown in Fig. 2 illustrate the onshore flow and approaching front. At this time, an atmospheric river is bringing moisture into the region, generating heavy precipitation over the mountains in the northern part of the subdomain, with lighter precipitation south of the frontal band. Over the ocean, southerly flow converges with more westerly flow just ahead of a narrow band of heavier precipitation. The NoCP experiments, and to some extent the other experiments, also show a band of precipitation located to the south of the frontal position at this time, stretching from the southwest corner of the subdomain to Cazadero (CZC), at the base of the coastal mountains. In general, the precipitation patterns in the experiments using the same $\mathrm{CP}$ are more similar to each other than the precipitation in the experiments using the same MP, suggesting a strong influence from subgrid convection. The simulations that include a $\mathrm{CP}$ all generate more light precipitation over the relatively warm ocean than the NoCP simulations.

\section{b. Observed and simulated reflectivity}

The observed radar reflectivity at CZC (Fig. 3) indicates light, intermittent rain showers during the first $9 \mathrm{~h}$ of the simulation period. Heavier rain begins between 1600 and 1700 UTC 15 February and continues into the morning of 16 February, followed by another period of light or intermittent precipitation. The height of the bright band, at which frozen hydrometeors begin to melt and become coated with a layer of water, is apparent at about $2 \mathrm{~km}$ prior to 0000 UTC 16 February.
The steady decrease in the brightband height on the morning of 16 February indicates that the melting level is becoming lower with time, as cooler air moves in from the northwest.

The simulated reflectivity at this location for the six model experiments (Fig. 4) shows that the timing of the reflectivity increase and the lowering of the brightband height is captured reasonably well by the model, for all experiments. In general, the Morrison scheme has higher reflectivity values than the Thompson scheme, especially during the period of heavier precipitation that began around forecast hour 10, and in the cold air above the bright band. Although higher reflectivity is typically associated with heavier precipitation, the rain rates shown at the bottom of Fig. 4 indicate that the Thompson experiments had slightly greater rain rates, with values closer to the observed, during this period of heavier rain.

Another significant difference between the simulations is in the reflectivity during the first $9 \mathrm{~h}$. While the NoCP and GF experiments show similar patterns for both MPs, the experiments in which the KF CP (Figs. 4c,d) is used show much stronger and more uniform reflectivity during hours $0-9$. The Thom-KF physics combination yields values greater than $20 \mathrm{dBZ}$ during this light rain period. The reflectivity values produced by the Morr-KF combination are smaller but less variable, suggesting more continuous rain than in either the observations, GF, or NoCP experiments.

From Fig. 4, we observe that 1) differences in the magnitude of the reflectivity appear to be related to the choice of microphysics scheme, and 2) the more continuous reflectivity signal during the first $9 \mathrm{~h}$ is linked to the choice of convective parameterization, and for the KF experiments appears to be inconsistent with the rain rates shown. In the following sections, we explore the reasons for these differences in reflectivity, primarily focusing on the first $9 \mathrm{~h}$.

\section{c. Relation of reflectivity to microphysical parameters}

The existence of a reflectivity signal indicates the presence of falling hydrometeors (rain, snow, or graupel).

TABLE 2. Parameter definition in the Thompson microphysics scheme. The fall speed relation for the Thompson scheme is $V_{k}(D)=\gamma c_{k} D^{d_{k}} \exp \left(-f_{k} D_{k}\right)$, in which the air density correction $\gamma=\left(\rho_{0} / \rho_{\text {air }}\right)^{0.5}$, and $\rho_{0}$ is the standard air density at sea level. Values for $c$, $d$, and $f$ for each species are given in the table.

\begin{tabular}{|c|c|c|c|c|c|c|c|c|}
\hline Species & $N_{0}$ & $\mu$ & $\rho$ & $a$ & $b$ & $c$ & $d$ & $f$ \\
\hline Cloud & Initial $\mathrm{CCN}=100 \times 10^{6} \mathrm{~m}^{-3}$ & - & 1000 & $\pi \rho_{w} / 6$ & 3 & $0.316946 \times 10^{8}$ & 2.0 & 0 \\
\hline Rain & Prognostic & 0 & 1000 & $\pi \rho_{w} / 6$ & 3 & 4854 & 1.0 & 195 \\
\hline Ice & Prognostic & 0 & 890 & $\pi \rho_{i} / 6$ & 3 & 1847.5 & 1.0 & 0 \\
\hline Snow $^{\mathrm{a}}$ & Temperature dependent & 0.6357 & 100 & 0.069 & 2 & 40 & 0.55 & 100 \\
\hline Graupel & $10^{4}$ to $3 \times 10^{6}$ & 0 & 500 & $\pi \rho_{g} / 6$ & 3 & 442 & 0.89 & 0 \\
\hline
\end{tabular}

${ }^{a}$ For snow in the Thompson scheme, the particle size distribution is a sum of exponential and gamma distributions 
TABLE 3. Parameter definition in the Morrison microphysics scheme. The fall speed relation for the Morrison scheme is $V_{k}(D)=\gamma c_{k} D^{d_{k}}$, and $\gamma=\left(\rho_{0} / \rho_{\text {air }}\right)^{0.54}$. Values for $c$ and $d$ for each species are given in the table, and $\rho_{0}$ is the standard air density at $850 \mathrm{hPa}$.

\begin{tabular}{llccccc}
\hline \hline Species & \multicolumn{1}{c}{$N_{o}$} & $\mu$ & $\rho$ & $a$ & $b$ & $c$ \\
\hline Cloud & Initial CCN $=250 \times 10^{6} \mathrm{~m}^{-3}$ & - & 997 & $\pi \rho_{w} / 6$ & 3 & $3 \times 10^{7}$ \\
Rain & Prognostic & 0 & 997 & $\pi \rho_{w} / 6$ & 3 & 841.997 \\
Ice & Prognostic & 0 & 500 & $\pi \rho_{i} / 6$ & 3 & 700 \\
Snow & Prognostic & 0 & 100 & $\pi \rho_{s} / 6$ & 3 & 11.72 \\
Graupel & Prognostic & 0 & 400 & $\pi \rho_{g} / 6$ & 3 & 19.3 \\
\hline
\end{tabular}

Simulated reflectivity from the WRF output is computed using

$$
Z_{k}=\frac{\left(\rho q_{k}\right)^{2}}{a_{k}^{2} N_{T k}}\left\{\frac{\Gamma\left(2 b_{k}+\mu_{k}+1\right) \Gamma\left(\mu_{k}+1\right)}{\left[\Gamma\left(b_{k}+\mu_{k}+1\right)\right]^{2}}\right\},
$$

where $Z_{k}$ is the linear reflectivity for each species $k$ (where $k$ is a precipitating hydrometeor), $\rho$ is the density of air, $q$ is the mixing ratio, $N_{T}$ is the total number concentration, $\Gamma$ is the gamma function, $a_{k}=\pi \rho_{k} / 6, b_{k}$ is a constant, and $\mu_{k}$ is the shape parameter. Values of $a, b$, and $\mu$ are given in Tables 2 and 3 , and are dependent on the density and particle shape assumptions in the MP. These values do not vary during the simulation; therefore, the quantity in brackets remains constant in time.

From Eq. (1), an increase in reflectivity indicates either an increase in the mixing ratio and/or a decrease in the number concentration. In Fig. 4, the disparity in reflectivity seen during hours 1-9 occurred in warm air, indicating that rain $(k=r)$ is the primary hydrometeor type contributing to the derived reflectivity at this time. Therefore, the KF experiments lead to more persistent $q_{r}$ in the atmosphere than the other experiments during the first $9 \mathrm{~h}$, and the Thom-KF experiment must have either higher values of $q_{r}$ or smaller quantities of $N_{r}$ than the Morr-KF experiment.

From Fig. 5, $q_{r}$ is generally greater and less variable in the two KF experiments during the period when reflectivity was anomalously strong, compared to the other experiments. Although the reflectivity values are largest in the Thom-KF experiment at this time, the $q_{r}$ magnitudes are largest in the Morr-KF experiment. The greater reflectivity in the Thom-KF run is due to smaller $N_{r}$ values (Fig. 6), suggesting larger drops. In this experiment, the number concentration of rain droplets is $<100 \mathrm{~kg}^{-1}$ for much of the first $9 \mathrm{~h}$. In contrast, the $N_{r}$ values for the Morr-KF experiment are much greater during this period, with magnitudes of more than $50000 \mathrm{~kg}^{-1}$. In fact, $N_{r}$ quantities in the Morr-KF run during this early period are much larger than during the $12-18$-h period, when the $q_{r}$ magnitudes are largest and rain rates are increased. Given identical mixing ratios, a larger number concentration would indicate smaller drops. In this case, the rain mixing ratios in the Thom-KF and Morr-KF runs differ by roughly an order of magnitude, while the number concentrations differ by approximately three orders of magnitude, indicating much smaller drops in the Morr-KF experiment. This is consistent with the simulated reflectivity of the first $9 \mathrm{~h}$, as small drops tend to produce a smaller reflectivity signal than large drops.

Figure 7 provides confirmation that the Thom-KF experiment produced mean drop diameters that are quite large compared to the other runs, particularly during light rain periods and when temperatures are below freezing. Furthermore, the positioning of larger drops above smaller drops is a physically unlikely scenario for saturated air. In comparison, the Morr-KF experiment produced very small rain droplets during the first $9 \mathrm{~h}$. During the main period of rain within the warm air, however, all experiments show generally similar drop sizes.

The importance of the drop size distribution (DSD) for weather and climate has been shown in multiple previous studies. For example, Twomey (1977) demonstrated that given the same liquid water path, an increase in cloud droplet number and a corresponding decrease in droplet size leads to increased reflectance from clouds for warm rain. Smaller cloud droplet size may also lead to increased cloud lifetimes due to slower coalescence to raindrop size (Albrecht 1989), since coalescence rate is a function of cloud drop effective radius. For raindrops, the fall speed is proportional to the drop size (Ferrier 1994), and therefore directly impacts the precipitation rate (see Tables 2 and 3 for fall speed relations).

It is apparent from Figs. 4-7 that the Thompson and Morrison microphysics schemes produce very different DSDs for rain when used with the KF CP than when used with no $\mathrm{CP}$ or the GF CP during the first $9 \mathrm{~h}$ of the simulation. In the case of the Thom-KF experiment, a small number of very large drops is produced, while in 

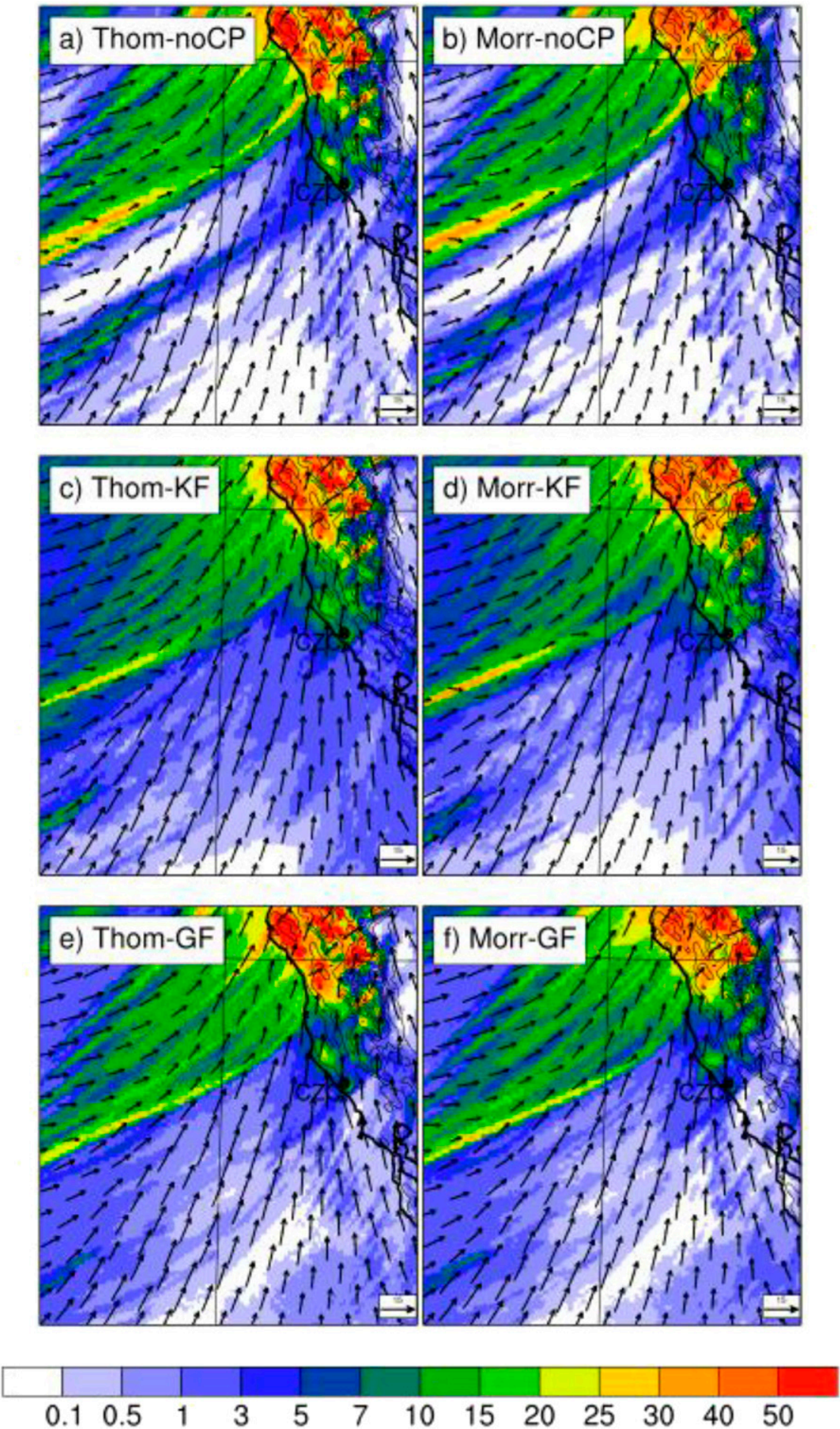

FIG. 2. Total accumulated precipitation $(\mathrm{mm})$ at $12 \mathrm{~h}$ for the six experiments listed in Table 1 , with wind vectors at the lowest model level, for the subdomain outlined in red in Fig. 1 (box A). The location of Cazadero, CA, is shown by the black dot labeled CZC. The reference vector is $15 \mathrm{~m} \mathrm{~s}^{-1}$.

the Morr-KF case, a huge number of tiny drops is generated during this period. In contrast, the rain DSDs in the other four experiments are relatively similar. From Tables 2 and 3 , the parameters $(a, b, \mu)$ that describe the theoretical particle size distribution for rain for both microphysics schemes are nearly 


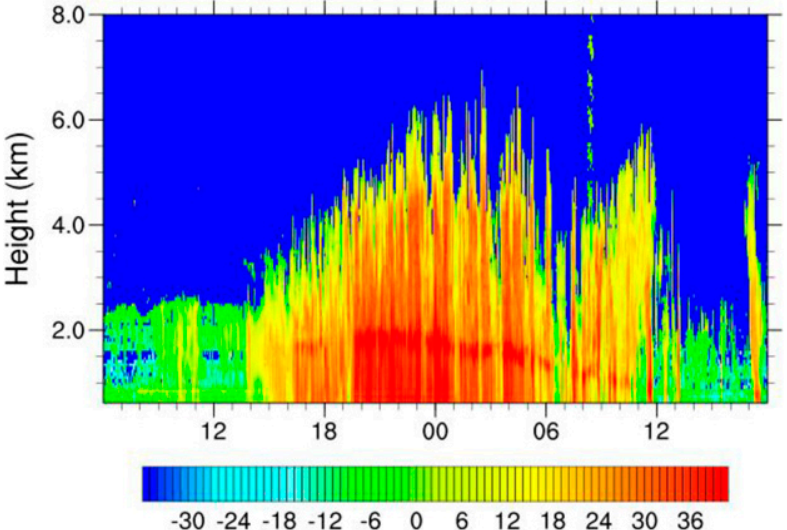

FIG. 3. Observed radar reflectivity $(\mathrm{dB} Z)$ from the S-band $(3 \mathrm{GHz})$ precipitation profiler for the time period from 0600 UTC 15 Feb to 1800 UTC 16 Feb 2011 at Cazadero, CA (CZC).

identical, yet clearly the actual DSDs for rain in the Thom-KF and Morr-KF simulations are quite different in this case.

\section{d. Budget analysis of rain number concentration $\left(N_{r}\right)$ tendencies}

Because microphysics is the only physical parameterization that directly modifies hydrometeor number concentrations by computing source and sink terms, budget analyses (Bao et al. 2016) of the microphysical tendencies for $N_{r}$ and $q_{r}$ were performed to identify the processes that lead to the differences in rain number concentration, mass, and consequently, in reflectivity and DSD. Vertical profiles of the budgets for the $N_{r}$ tendencies in the KF and NoCP experiments (Fig. 8) were computed using averages in time (hours 1-9) and in space over the $25 \times 25$ gridpoint box called "box B" in Fig. 1. Averaging over this small box includes the processes that are occurring at $\mathrm{CZC}$, as well as the processes that impact the air immediately upstream. For reference, similarly averaged vertical profiles of $q_{r}$ and $N_{r}$ for the six experiments are presented in Fig. 9. Results from the budget analyses for the GF experiments were nearly
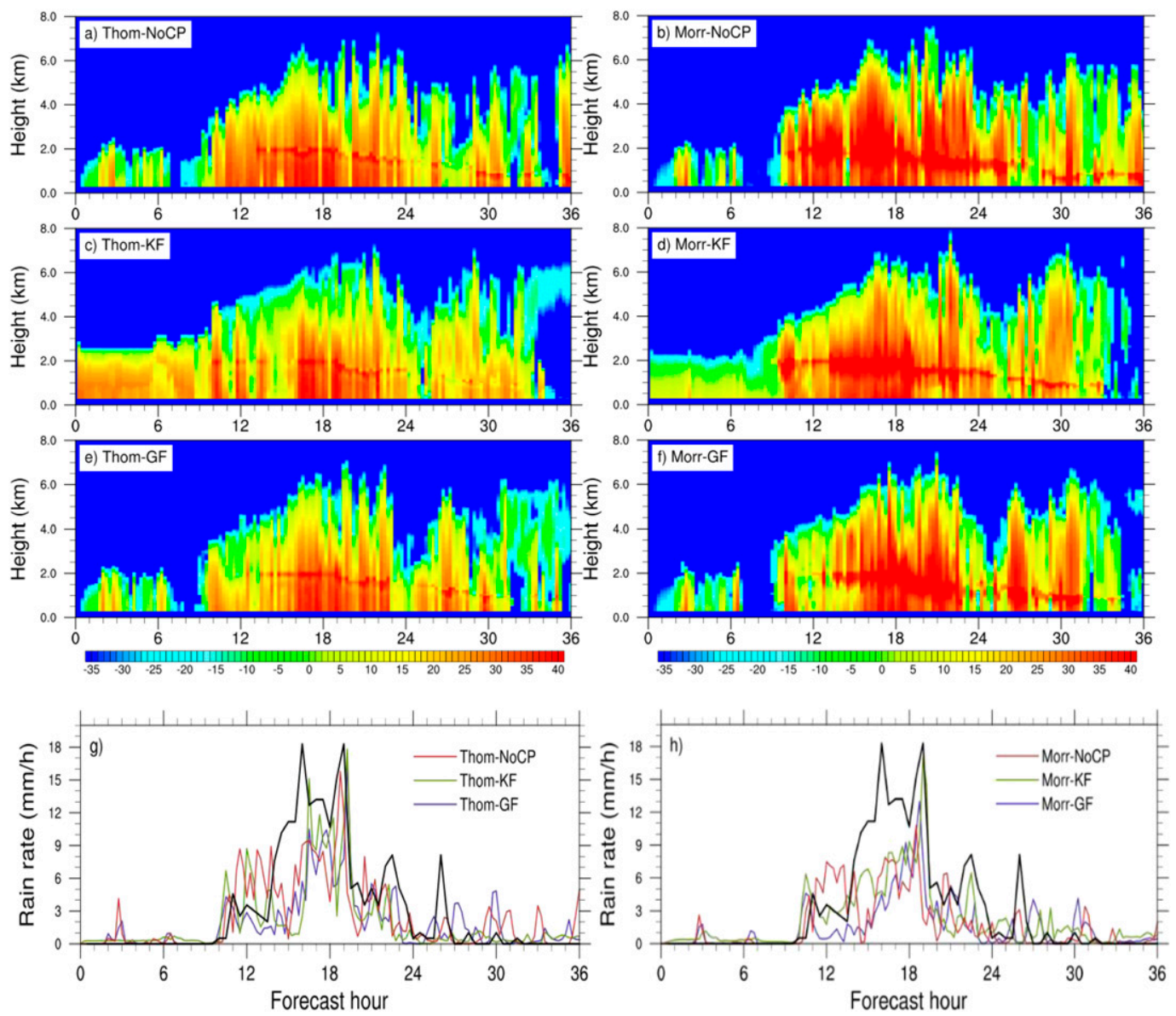

FIG. 4. (a)-(f) Time-height series of reflectivity (dBZ) computed from WRF output for simulations using (left) the Thompson microphysics and (right) the Morrison microphysics parameterization. (top) The experiments in which no cumulus parameterization was used, (middle) runs using the Kain-Fritsch CP, and (bottom) experiments using the GrellFreitas CP. (g),(h) Time series showing the rain rates $\left(\mathrm{mm} \mathrm{h}^{-1}\right)$ for the three experiments shown above, along with the observed rain rate at Cazadero (heavy black curve). 

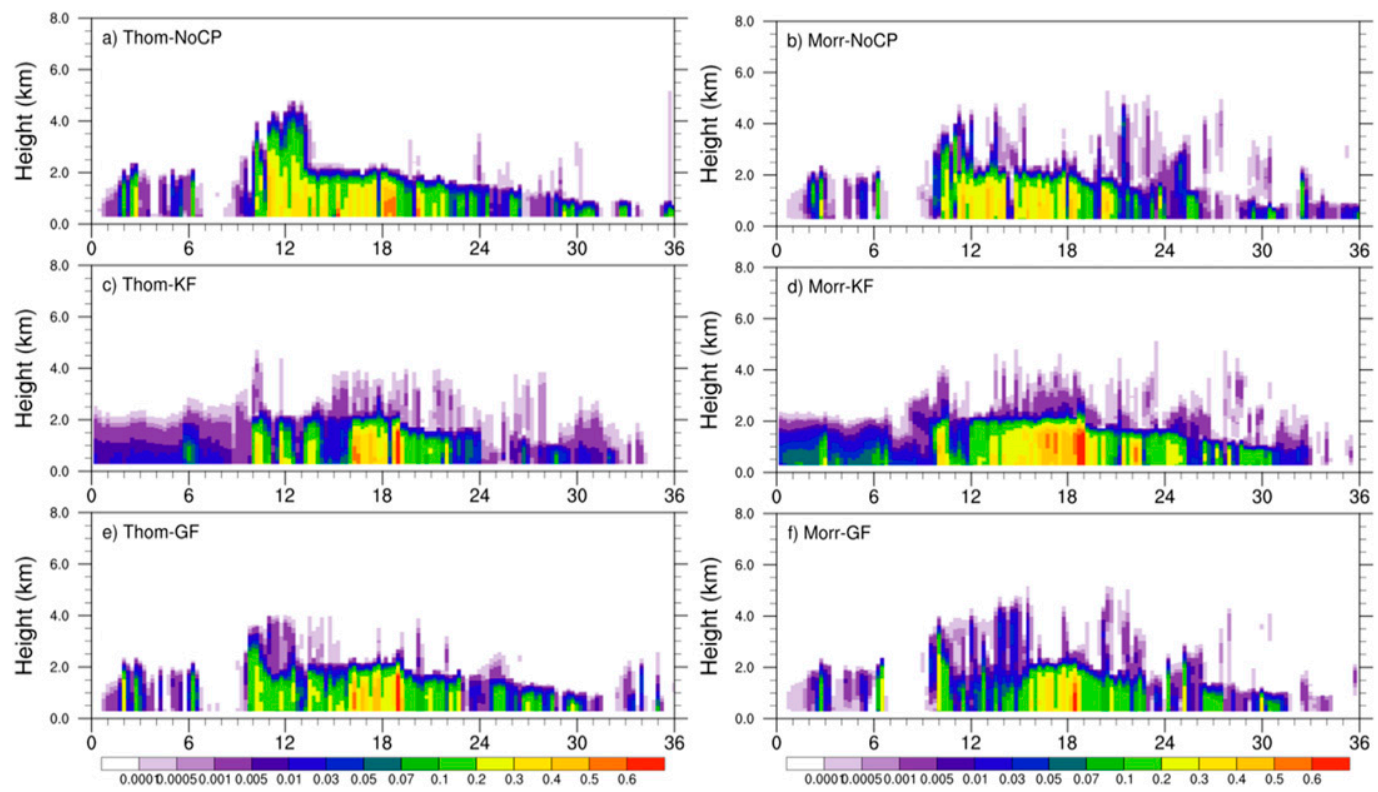

FIG. 5. Time-height series of rainwater mixing ratio $\left(\mathrm{g} \mathrm{kg}^{-1}\right)$ at Cazadero, CA, from (left) the Thompson experiments and (right) the Morrison experiments. The $x$ axis is the forecast hour.

identical to those for the NoCP experiments and are not shown. All process terms have been included in the budgets, although many do not contribute significantly at this time and are not discussed. Dynamical processes such as advection and diffusion also contribute to the overall tendencies but are not included in this analysis.

Despite using different MPs, the $N_{r}$ budgets in the two NoCP experiments (Figs. 8a,b) show some strong similarities. In both experiments, production is dominated by autoconversion, a term that describes the number of tiny droplets that grow large enough, via collision and coalescence, to become categorized as raindrops rather than cloud drops. Sedimentation is the primary removal mechanism. Sedimentation is a sink in the upper portion of the cloud layer, but a source at lower levels, as droplets fall but have not yet reached the
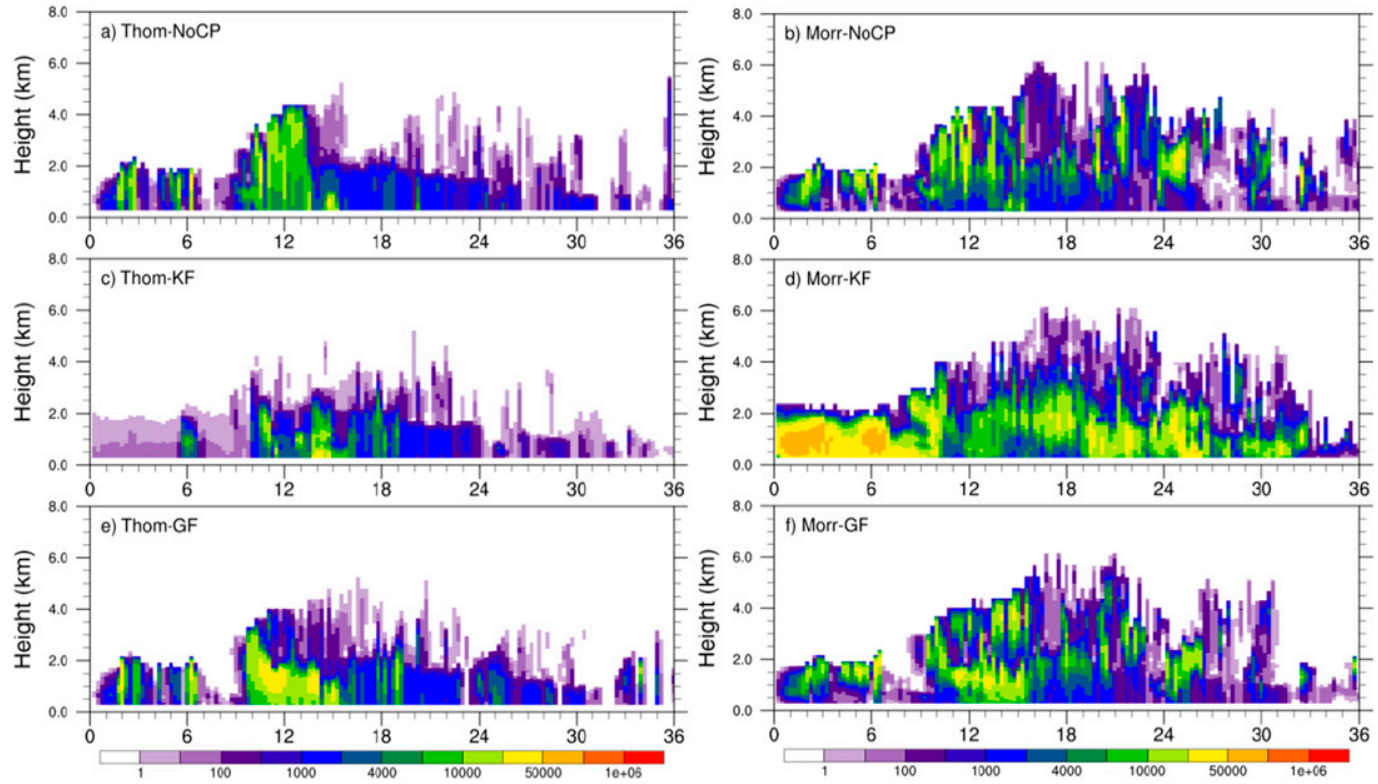

FIG. 6. As in Fig. 5, but for number concentration $\left(\mathrm{kg}^{-1}\right)$ of rain. 

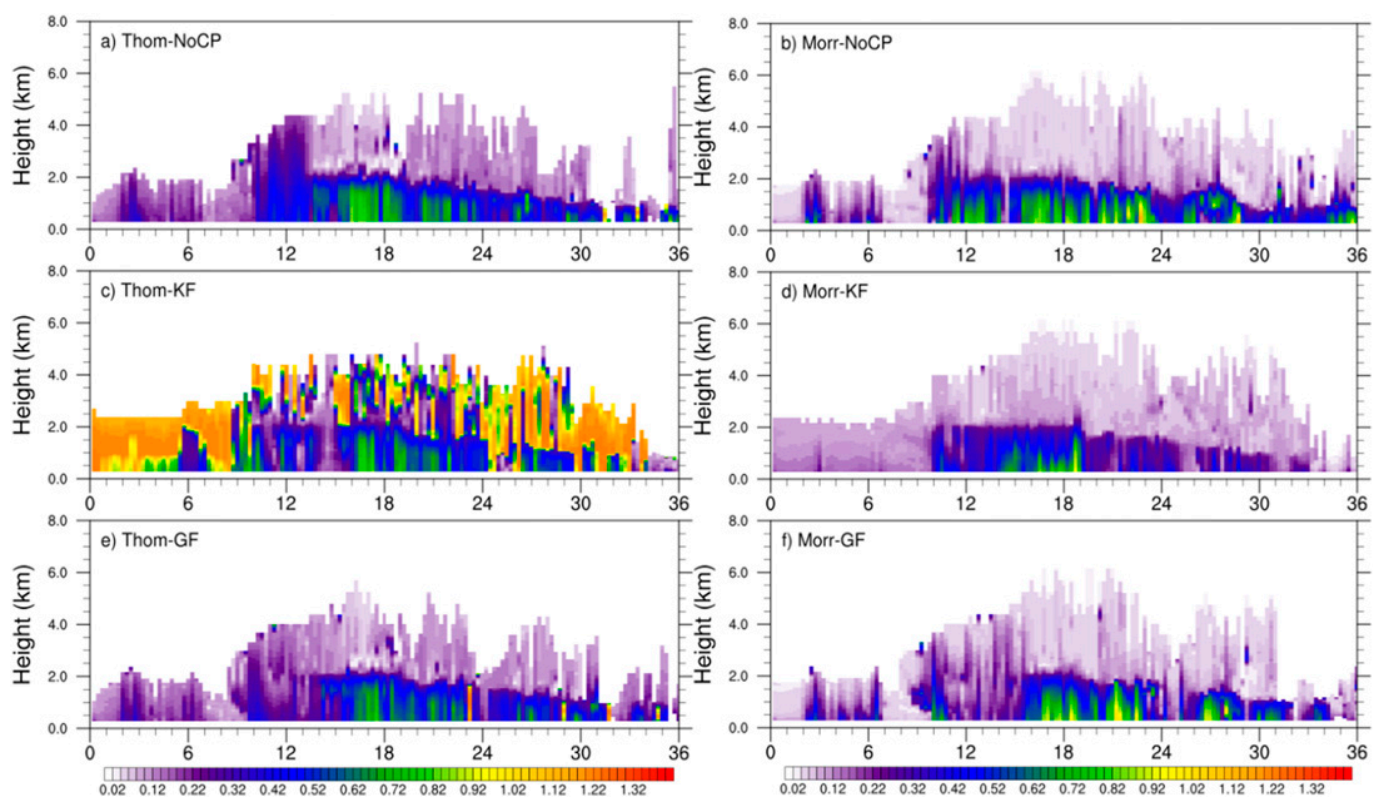

FIG. 7. As in Fig. 5, but for the mean diameter ( $\mathrm{mm})$ of raindrops.

ground. Additional processes that decrease $N_{r}$ in both experiments include evaporation and self-collection (i.e., rain collecting other raindrops, also called aggregation). In the Morr-NoCP experiment an additional term appears as a sink of significant magnitude, the term is labeled "Adjust2." This term does not result from any physical process, but rather it accounts for changes to $N_{r}$ forced by a bounds test in the code, included to ensure that the magnitude of $N_{r}$ is consistent with that of $q_{r}$, in order to maintain a specified range of drop sizes. In this case, the updated $N_{r}$ was too large, and was reduced. This adjustment term is similar in magnitude to evaporation and self-collection, suggesting that the production terms may be unrealistically large in this case, or the other destruction terms too small.

When the KF CP is applied, the magnitude and profiles of the microphysical processes are quite different. For the Thom-KF run (Fig. 8c), the $N_{r}$ budget terms are approximately an order of magnitude smaller, and while generally the same processes are dominant, the vertical distribution of the terms changes. There are two maxima in the autoconversion and sedimentation terms, and the profiles extend higher, suggesting increased upward transport of moisture by the CP. As a result, terms due to the interaction of rain and frozen species begin to play a greater role in the $N_{r}$ budget. In addition, one of the adjustment terms becomes significant in the ThomKF run: the Adjust2 term. Like the adjustment term in the Morr-NoCP experiment, this term accounts for changes in $N_{r}$ made in order to maintain a specified range of drop sizes, consistent with the magnitude of $q_{r}$.
In the Thompson MP, raindrops are required to have a median volume diameter (MVD) between 0.037 and $2.5 \mathrm{~mm}$. In this case, the adjustment term is positive, indicating that $N_{r}$ was increased to maintain an appropriate MVD.

Because the $N_{r}$ budgets for both the Thompson and Morrison schemes include adjustment terms of significant size, it is worthwhile noting that adjusting the number concentration rather than the mixing ratio is a logical choice. Changing $q_{r}$ would have thermodynamic consequences that changing $N_{r}$ does not have. In addition, number concentration is a more poorly observed and understood quantity than mixing ratio, and the equations for the processes contributing to the number concentration tendencies may be less accurate than those for mixing ratio. There are many uncertainties in the computation of microphysical processes, and the relative magnitudes of the individual processes are often difficult to quantify via observations.

For the Morr-KF experiment (Fig. 8d) the magnitude of the $N_{r}$ budget terms is approximately 100 times larger than for the Thom-KF. In this experiment, autoconversion plays a very minor role in the $N_{r}$ budget, and loss by evaporation is larger than loss due to sedimentation or self-collection. Increased evaporation is consistent with the smaller drop size in this experiment, as smaller drops evaporate more readily than large drops because of their increased ratio of surface area to mass. By far, the largest source term at this time is the contribution from the cumulus parameterization, a term not present in the Thompson scheme. It represents the 

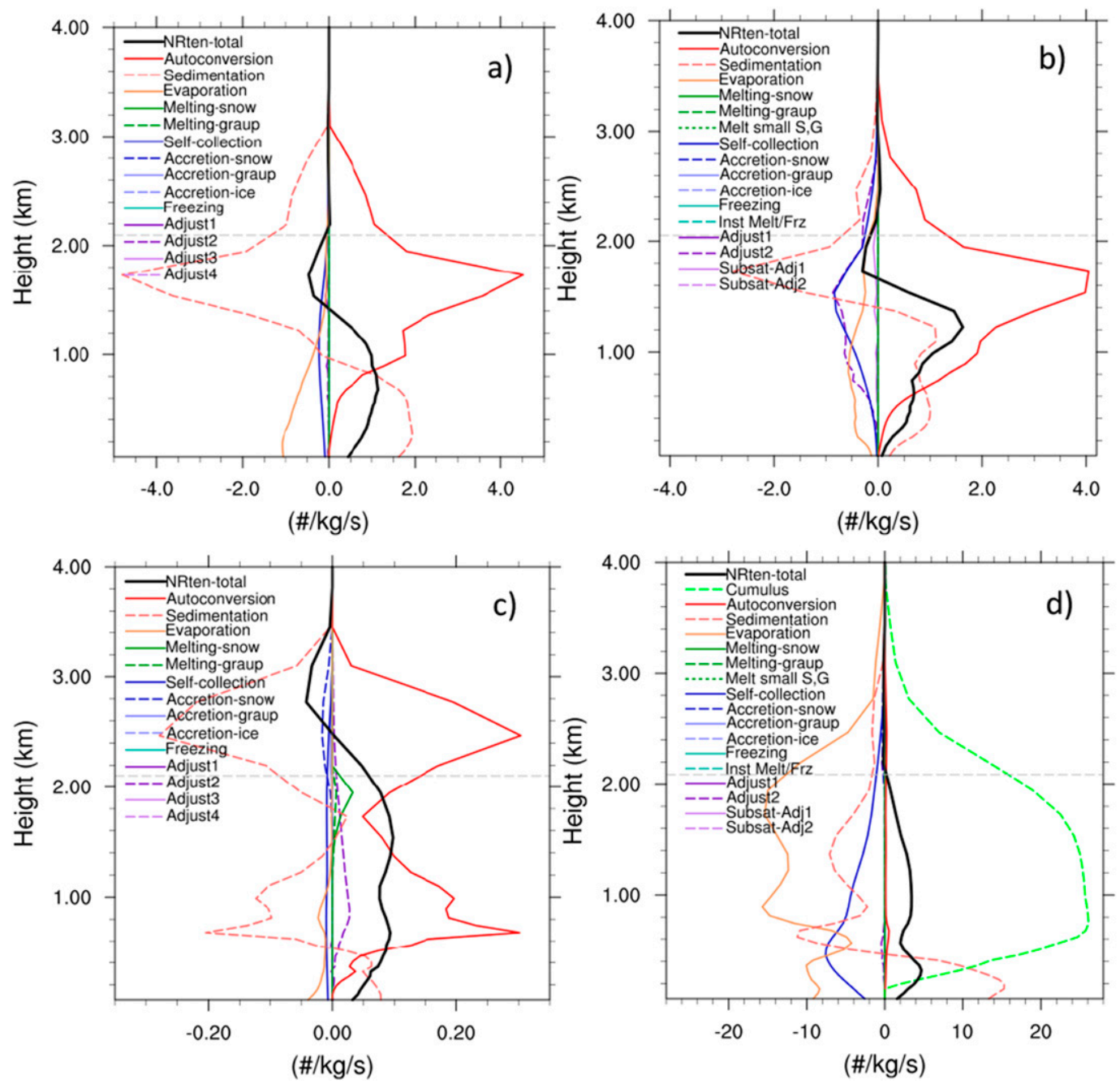

FIG. 8. Vertical profiles of horizontally and temporally averaged budget terms for the rainwater number concentration $\left(N_{r}\right)$ tendencies for the (a) Thom-NoCP, (b) Morr-NoCP, (c) Thom-KF, and (d) Morr-KF experiments. Spatial averaging was over box B, and temporal averaging was over forecast hours 1-9. Note that the horizontal scales differ between experiments. The horizontal dashed gray line is the $0^{\circ} \mathrm{C}$ line. The heavy black line is the total tendency (sum of all other terms).

change in $N_{r}$ corresponding to the change in $q_{r}$, which directly results from the convective tendencies. Because the CP is single moment (i.e., it does not compute a number concentration tendency but only a mixing ratio tendency), an assumption is made regarding the size distribution of particles associated with the mixing ratio tendencies from convection, which are input variables to the Morrison scheme. An intercept parameter $N_{0}$ is defined, as is typically done in a single-moment scheme, and the change in number concentration due to convection is computed from

$$
N_{k}=\frac{N_{0 k} \Gamma\left(\mu_{k}+1\right)}{\lambda_{k}^{\mu_{k}+1}} .
$$

The slope parameter $\lambda$ is calculated using $q$ from convection and the specified DSD parameters in the usual formula:

$$
\lambda_{k}=\left[\frac{a_{\mathrm{mk}} N_{0 k} \Gamma\left(b_{m k}+\mu_{k}+1\right)}{\rho q_{k}}\right]^{1 /\left(b_{m k}+\mu+1\right)} .
$$

In the Morrison MP, $N_{0 r}=10^{7} \mathrm{~m}^{-4}$, a value slightly larger than the value of $8 \times 10^{6} \mathrm{~m}^{-4}$ that was observed by Marshall and Palmer (1948) and is frequently used in single-moment microphysics schemes. For ice, the convective contribution to number concentration is calculated by assuming a mean volume diameter of $80 \mu \mathrm{m}$. The mass is then computed using the following massdiameter relation: 

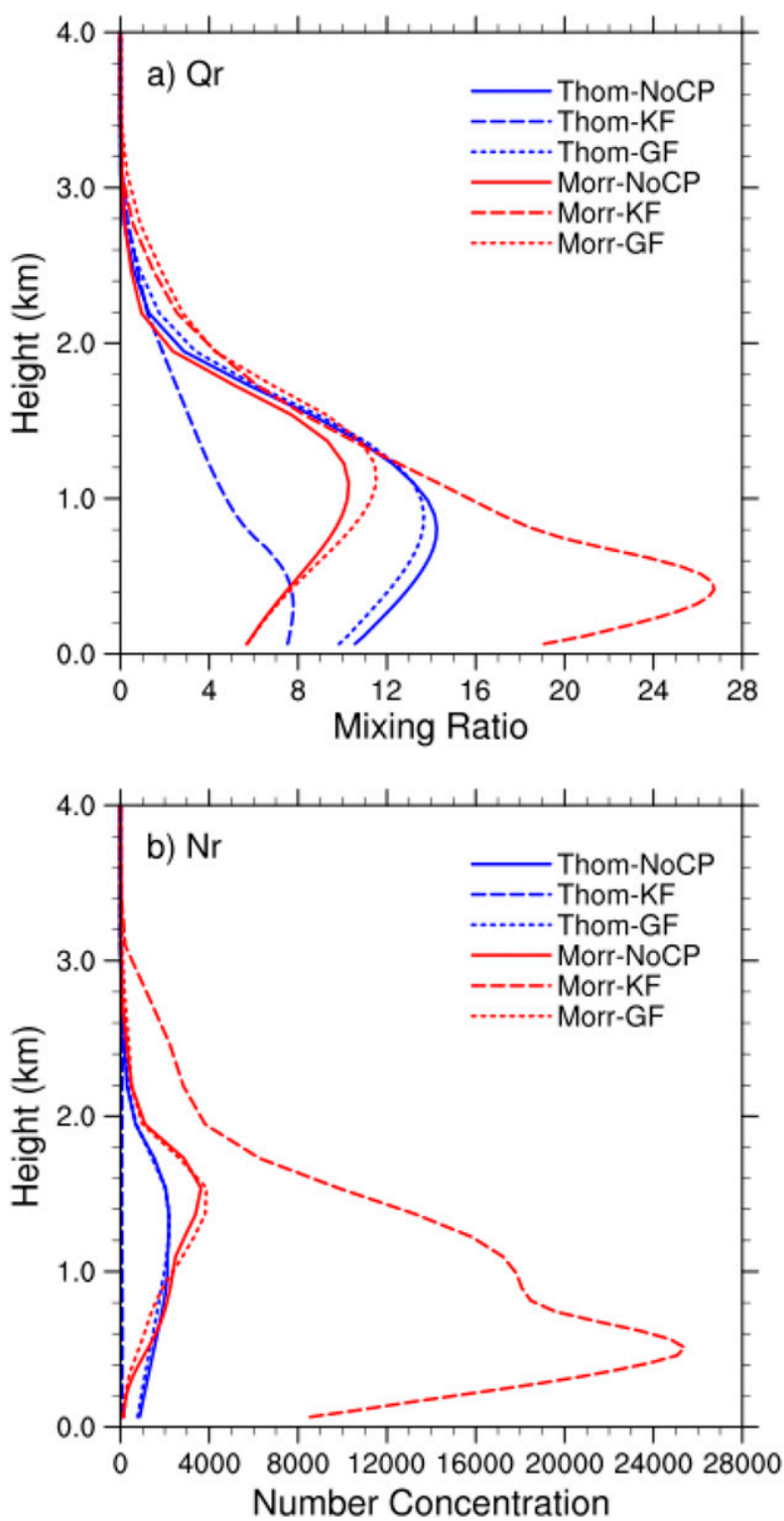

FIG. 9. Vertical profiles of (a) rain mixing ratio $\left(\times 10^{6} \mathrm{~kg} \mathrm{~kg}^{-1}\right)$ and (b) rain number concentration $\left(\mathrm{kg}^{-1}\right)$ for the six experiments, averaged in time for hours 1-9 and in space over box B (refer to Fig. 1).

$$
m_{k}=a_{k} D^{b_{k}}
$$

A mean number concentration can be derived from $N=q / m$.

Because the Kain-Fritsch CP contributes significantly to the net change in $q_{r}$ but does not consider changes in $N_{r}$, the difference in the $q_{r} / N_{r}$ ratio between the Thom$\mathrm{KF}$ and Morr-KF experiments is largely a result of the way the MP handles the contribution from convection. Since the Morrison scheme includes a term to estimate the change in $N_{r}$ associated with the convective contribution, while the Thompson scheme does not, the resulting $N_{r}$ in the Morr-KF run is much larger than in the Thom-KF run, especially during the first $9 \mathrm{~h}$ of these simulations. The positive contribution of the balance term in the $N_{r}$ budget for the Thom-KF run (Fig. 8c) was necessary because the microphysical tendency for $N_{r}$ resulted in number concentrations that were too small. The omission of this term in the Thompson scheme should not be considered a flaw in the scheme but rather a design feature reflecting the intended application of the scheme on scales at which a convective parameterization is not typically used. Furthermore, the assumption used in the Morrison scheme to estimate the convective contribution to $N_{r}$ may not be consistent with the explicit computation of $N_{r}$ by the two-moment microphysics scheme. The anomalous reflectivity in Fig. 4, and the larger values of $N_{r}$ in Figs. 6 and 9 for the MorrKF run compared to the Morr-NoCP run, all suggest that the $N_{r}$ associated with convection in the Morr-KF experiment may be too large in this case, leading to unrealistically small droplets.

The profiles of $q_{r}$ and $N_{r}$ in Fig. 9 show that the MorrKF experiment not only has much higher $N_{r}$ values, but also larger values of $q_{r}$ at low levels, compared to the other experiments. The difference is very likely a result of the differing DSDs, as the smaller drops in the Morr$\mathrm{KF}$ run are more likely to remain suspended in the air, while the very large drops of the Thom-KF simulation will fall to the ground as precipitation.

\section{e. Budget analysis of rain mixing ratio tendencies from microphysics}

Temporal and spatial averages of the $q_{r}$ budget terms from microphysical processes for the NoCP and KF experiments are also computed (Fig. 10). Again, when no CP is used, the Thompson and Morrison schemes have strong similarities in the sources and sinks of $q_{r}$. Above $1 \mathrm{~km}$, for both MPs, rain production via collection of cloud droplets (the term labeled "AccretionCldW") is nearly balanced by loss due to sedimentation. At low levels, evaporation is the primary sink. Autoconversion is a significant source term in the ThomNoCP run; this term is not significant in the Morr-NoCP run at this time. Although autoconversion was the largest production term in the $N_{r}$ budgets, these drops are tiny and have a relatively small amount of mass. In both NoCP experiments, the net change in $q_{r}$ (heavy black line) indicates increased rainwater mass in the lowest $1.3-1.5 \mathrm{~km}$, with a slight loss above.

In contrast, when convection from the KF scheme is included (Figs. 10c,d), the net tendency for $q_{r}$ due to microphysical processes is almost entirely negative, except in the lowest $300 \mathrm{~m}$. The two KF experiments have 

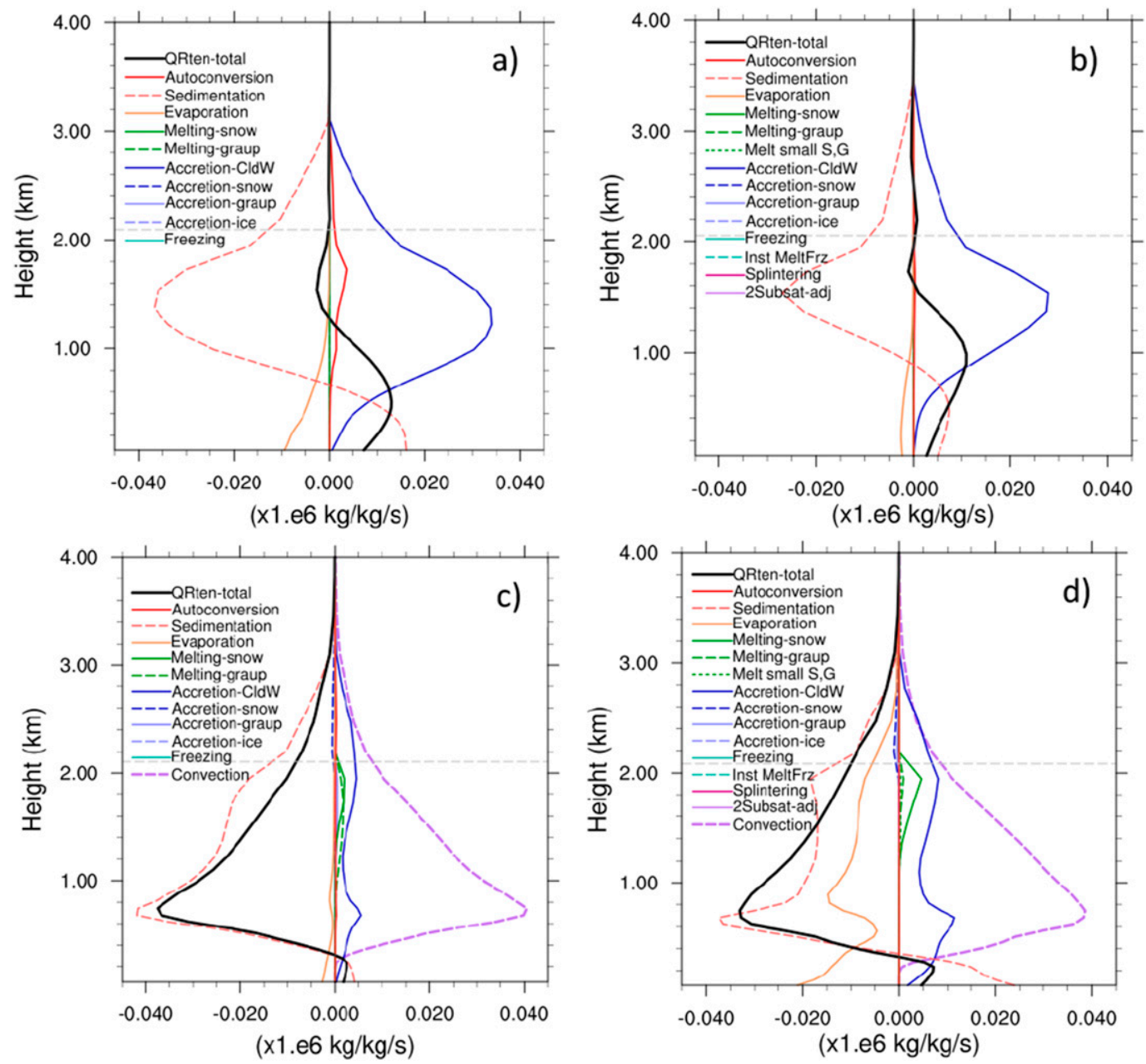

FIG. 10. (a)-(d) As in Fig. 8, but for the budget terms of the rainwater mixing ratio $\left(q_{r}\right)$ tendencies. In addition, the $q_{r}$ tendency from convection has been added to (c) and (d) (dashed purple line).

similar total tendencies, and are similar in their contributing terms: collection of cloud drops and melting are source terms, and sedimentation and evaporation are sink terms. As in the $N_{r}$ budget analyses, the evaporation term is much larger in the Morr-KF run, which has more small droplets. The collection term is also larger in this experiment. Also included in Figs. 10c and $10 \mathrm{~d}$ is the $q_{r}$ tendency from convective detrainment. In both experiments, detrained rainwater from the KF CP scheme is nearly equal in magnitude but opposite in sign to the net microphysical $q_{r}$ tendency, so that the role of the microphysics is primarily to remove $q_{r}$ produced by convection.

\section{f. Accounting for the cumulus parameterization tendencies in the microphysics}

Given the importance of the treatment of detrained hydrometeors from the $\mathrm{CP}$ by the MP, a set of sensitivity experiments was performed in which the convective tendencies for $q_{r}$ and $q_{i}$ are used to compute a change in the corresponding second moment $\left(N_{r}, N_{i}\right)$ in the Thompson MP, similar to the approximations made in the Morrison scheme. In all experiments, the KainFritsch CP was used with a modified Thompson MP scheme. For efficiency, very simple relationships between the mixing ratio and the number concentration were tested in these experiments. Because the largest differences in the initial set of experiments were seen during the first $9 \mathrm{~h}$ when the temperatures were above freezing, these experiments focus on the impact on $N_{r}$, rather than $N_{i}$. Experiment descriptions are given in the following paragraphs, and summarized in Table 4.

The first two sensitivity tests were designed to test the range of the potential impact. The tests assumed that the mean diameter of the rain and ice particles had (i) the minimum MVD and (ii) the maximum MVD. Using 
TABLE 4. Description of sensitivity experiments.

\begin{tabular}{|c|c|c|}
\hline Expt & Size distribution assumption-rain & Size distribution assumption-ice \\
\hline MinMVD & $\operatorname{MVD}($ rain $)=37.5 \mu \mathrm{m}$ & $\operatorname{MVD}($ ice $)=20 \mu \mathrm{m}$ \\
\hline MaxMVD & $\operatorname{MVD}($ rain $)=2.5 \mathrm{~mm}$ & $\operatorname{MVD}($ ice $)=300 \mu \mathrm{m}$ \\
\hline Constant $N_{0 r}$ & $N_{0 r}=10^{7} \mathrm{~m}^{-4}$ & $\operatorname{MVD}($ ice $)=80 \mu \mathrm{m}$ \\
\hline$N_{0 r}=f\left(q_{r}\right)$ & $N_{0 r}=f\left(q_{r}\right)$ after Pan et al. (2016) & $\operatorname{MVD}($ ice $)=80 \mu \mathrm{m}$ \\
\hline DfromMP & \multicolumn{2}{|c|}{$Q_{\mathrm{MP}}=q_{\text {tot }}-q_{\mathrm{CP}}, Q_{\mathrm{MP}} / N_{\text {old }} \rightarrow D \rightarrow N_{\text {new }}$} \\
\hline
\end{tabular}

this value for the diameter $D$ in Eq. (4), the mean mass $m_{\mathrm{CP}}$ of the species was computed and applied in the simple relation $N_{\mathrm{CP}}=q_{\mathrm{CP}} / m_{\mathrm{CP}}$, where the subscript CP indicates a quantity from the convective parameterization. In the Thompson scheme, the minimum MVD for rain is $37.5 \mu \mathrm{m}$ and for ice is $20 \mu \mathrm{m}$, while the maximum MVDs are $2.5 \mathrm{~mm}$ (rain) and $300 \mu \mathrm{m}$ (ice). These are the values applied as a mean diameter for the convective component.

The third experiment used the same assumptions as are used in the Morrison scheme, in which a constant intercept parameter for rainwater $\left(N_{0 r}=10^{7} \mathrm{~m}^{-4}\right)$ is used to determine the corresponding $N_{r}$. For ice, an MVD of $80 \mu \mathrm{m}$ was assumed. These DSD assumptions are typical of those used in single moment bulk MPs.

Several authors (Thompson et al. 2004; Zhang et al. 2008; Pan et al. 2016, among others) have explored the relationship between $q_{r}$ and $N_{r}$ based on rain DSDs in observational and model environments and have developed equations expressing $N_{0 r}$ as a function of $q_{r}$, or water content $W$. In a fourth experiment, the relation of Pan et al. (2016) was used to compute $N_{0 r}$ for the convective component of $q_{r}$, following their Eq. (11):

$$
N_{0 r}=c_{r}\left(1000 \rho q_{r}\right)^{d_{r}},
$$

where $c_{r}=5.13 \times 10^{5}$ and $d_{r}=-1.075$. These values are based on a least squares fit derived from a control simulation of a squall line. In this experiment, for ice it was again assumed that the MVD was $80 \mu \mathrm{m}$, as no coefficients for ice were provided in the Pan et al. (2016) paper. The $N_{0}-W$ relation of Zhang et al. (2008) was also tested, but the results were very similar to those of the MaxMVD experiment and are not shown here.

To determine the parameters for an additional sensitivity test, the mixing ratios without the convective tendencies were assumed to be consistent with the number concentrations. Therefore, the convective contribution was subtracted from the mixing ratios and the remaining mixing ratio used, with the number concentrations, to compute the mean particle diameters. This estimated diameter was then applied to the convective mixing ratio tendencies, to compute a convective number concentration contribution. If the mixing ratio without the contribution from convection was below a computational threshold, specified intercept parameters were used to compute the convective $N_{r}$ and $N_{i}$. This experiment is labeled "DfromMP."

By comparing the computed reflectivity, raindrop diameters, $q_{r}$, and $N_{r}$ from these experiments (Fig. 11), the impact of these size distribution assumptions applied to the convective contribution is evident. In the MinMVD experiment (Fig. 11, top panels), in which the rain and ice particles contributed by the convective parameterization are very small, more droplets remain suspended in the air since the particle fall speeds are reduced. As a result, lower reflectivity, larger rain mixing ratios, and very large number concentrations are present. When these particles are assumed to be at the large end of the allowable size spectrum, as in the MaxMVD experiment (Fig. 11, second panels), reflectivity magnitudes are large, but the number concentrations are small, as the mass is contained in fewer, larger drops that precipitate out of the atmosphere at a faster rate.

For the $N_{0 r}=f\left(q_{r}\right)$ experiment (fourth panels), the results shown are similar to the MaxMVD experiment, indicating that the DSD assumption in this relation, derived from a squall-line study, may be leading to drop sizes that are too large for this case. In the "DfromMP" experiment (bottom panels), $N_{r}$ appears to be too large, with diameters too small. The DSD produced by the "Constant $N_{0 r}$ " experiment falls in between the other experiments and is perhaps the most realistic.

Figure 12 gives an indication of the impact that varying the DSD can have on precipitation. With smaller drops, less light rain falls over the ocean. In addition, the frontal rainband moves slightly faster in the MaxMVD run, compared with the MinMVD experiment.

By comparing these results with the observed reflectivity (Fig. 3) it is clear that none of these sensitivity experiments produces an ideal solution. While this approach may improve upon the results seen in the ThomKF experiment with regard to consistency between mass and number of particles, in all experiments, the rain mixing ratios and associated reflectivity shown are more uniform and less intermittent than those observed during the 0-9-h period. In some experiments, the derived reflectivity patterns are at times unlike any observations, 


\section{a) Reflectivity}
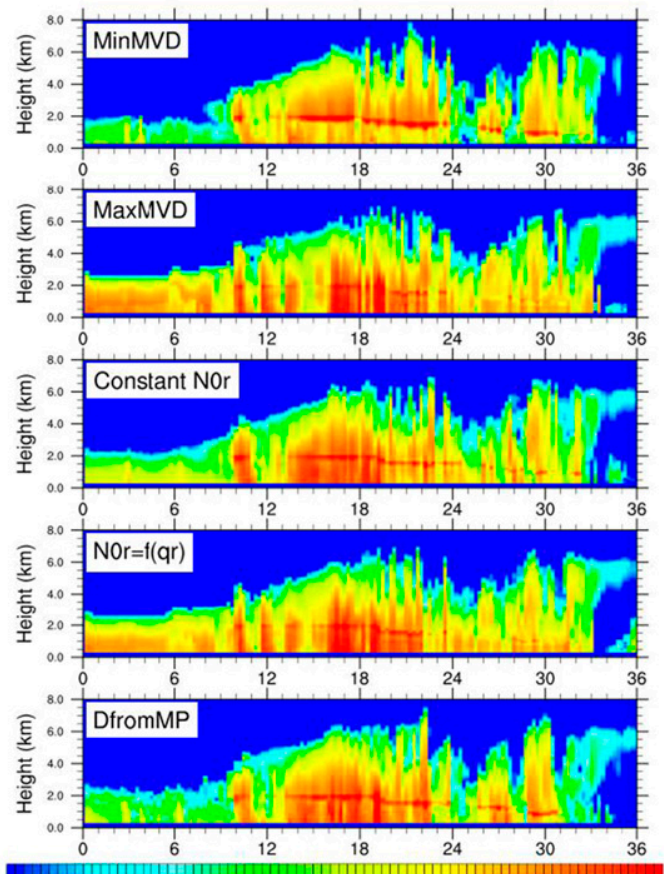

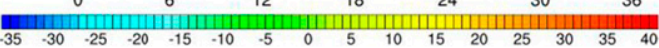

\section{b) Diameter of rain drops}
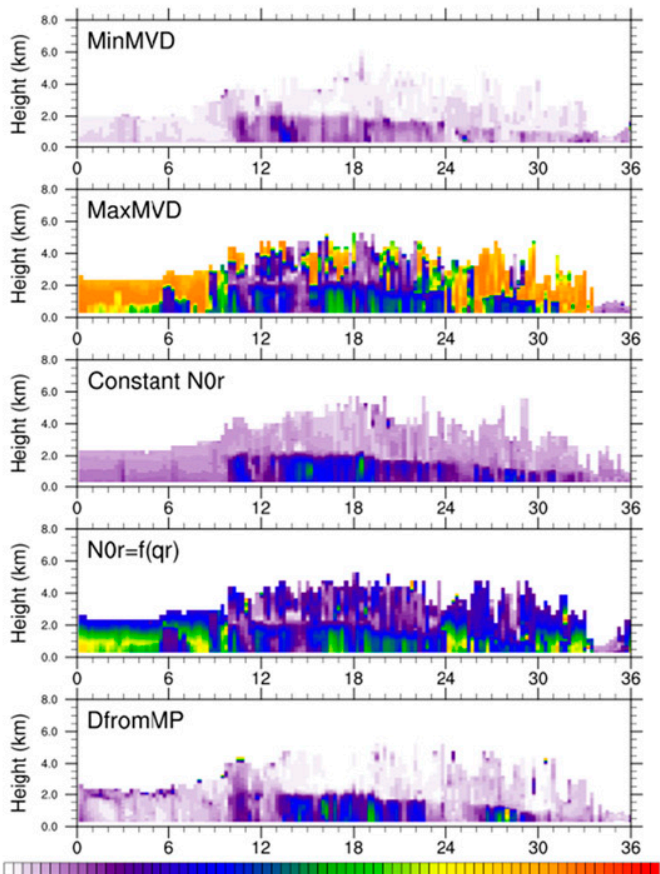

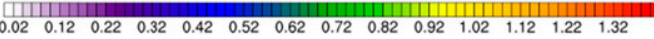

\section{c) Rain mixing ratio}
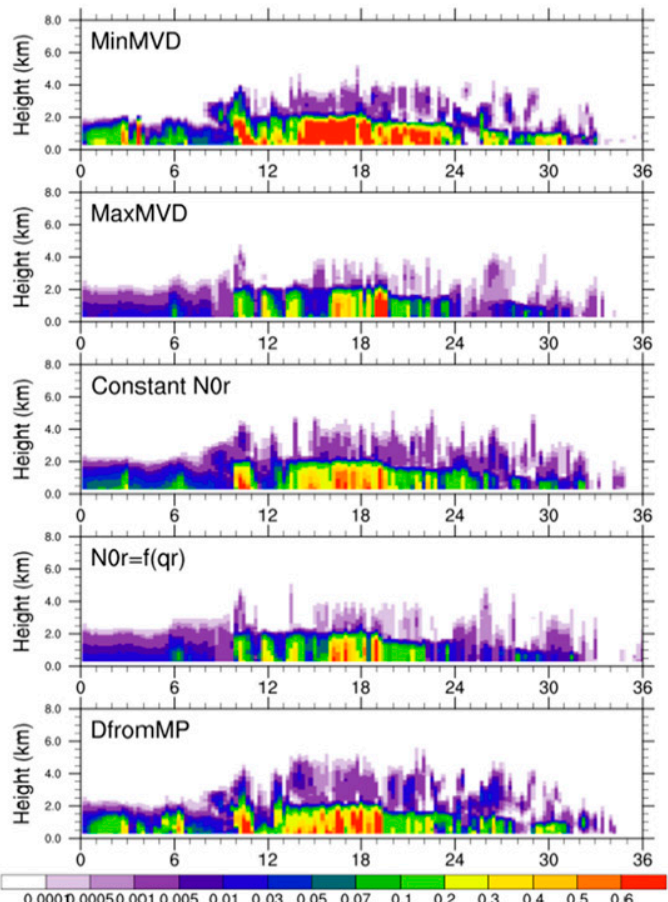

\section{d) Rain number concentration}

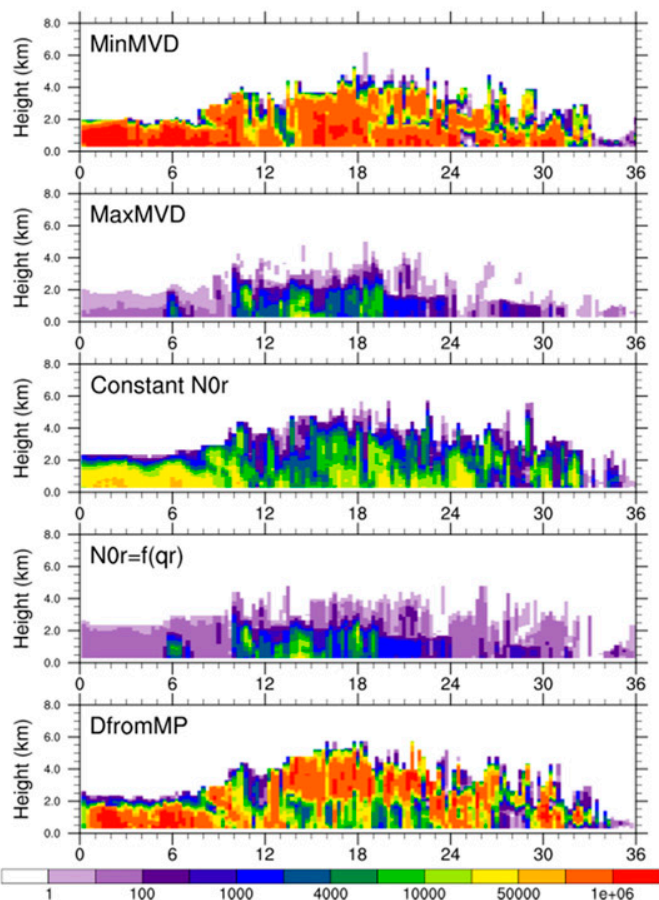

FIG. 11. Time-height series at CZC for (a) simulated reflectivity (dBZ), (b) raindrop diameters (mm), (c) rain mixing ratios $\left(\mathrm{g} \mathrm{kg}^{-1}\right)$, and (d) rain number concentrations $\left(\mathrm{kg}^{-1}\right)$, for the five Thom $+\mathrm{KF}$ experiments in which various DSD assumptions are used to calculate $N_{r}$ and $N_{i}$ for the convective component of the $q_{r}$ and $q_{i}$ tendencies. 

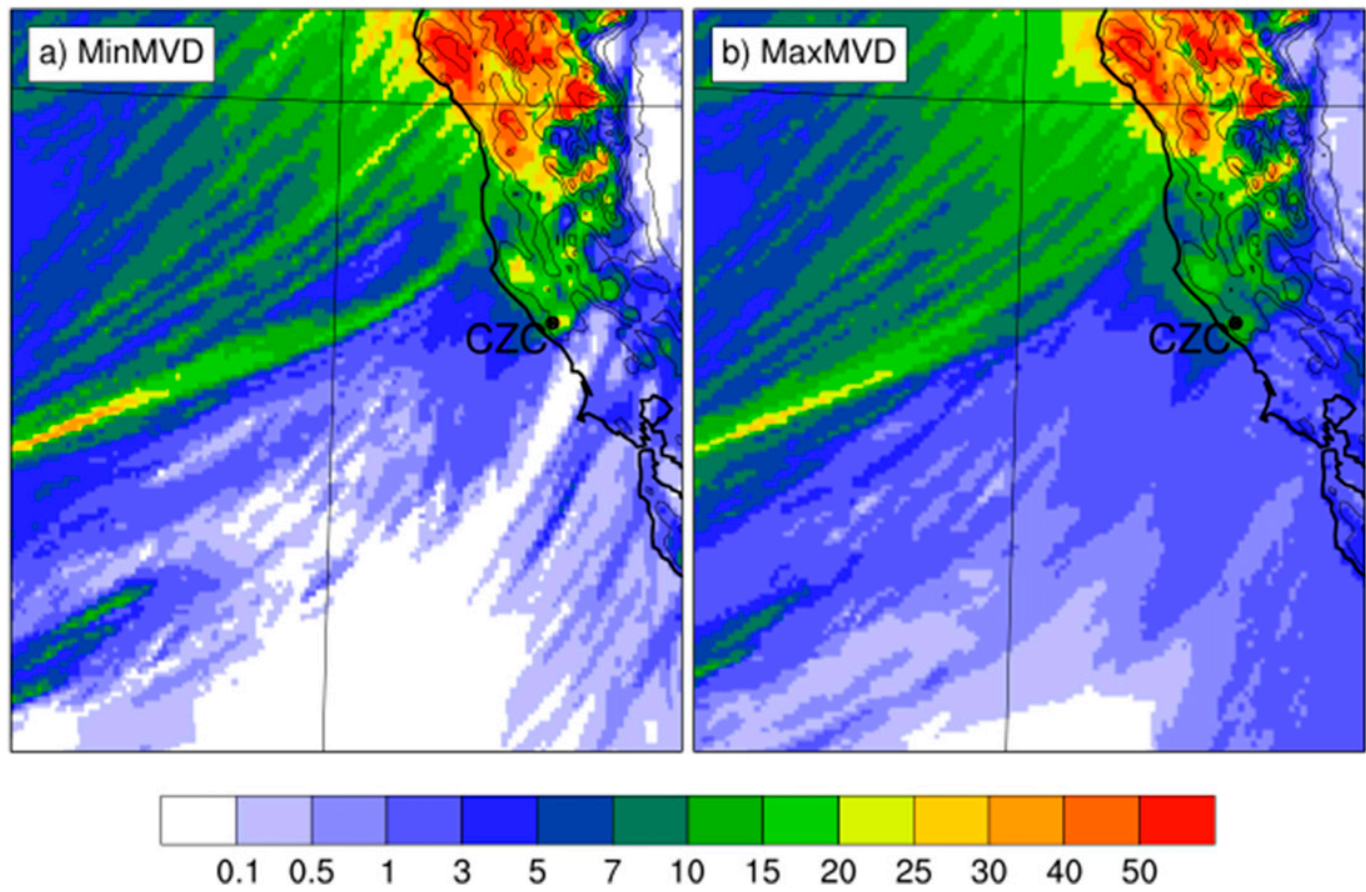

FIG. 12. Total accumulated precipitation $(\mathrm{mm})$ at $12 \mathrm{~h}$ for the modified Thom-KF experiments using (a) minimum MVD for rain and (b) maximum MVD for rain. The region shown is the subdomain labeled box A in Fig. 1. The location of Cazadero, CA, is indicated by the black dot labeled CZC.

with stronger reflectivity found above lower values (e.g., hours $12-24$ in the MinMVD experiment). In addition, the bright band is sometimes a minimum signal rather than a maximum (e.g., hours 26-30 in the MaxMVD experiment). These unrealistic reflectivity values indicate that an inconsistency still exists between the mixing ratios and number concentrations or intercept parameters used to compute the reflectivity.

\section{g. Analysis of the convective parameterization schemes}

While the previous analysis has focused on the microphysical response to the parameterized convection, it is also evident that the two CPs used in this study react very differently to the model atmosphere. For example, the consistent presence of higher values of $q_{r}$ at CZC during the first $9 \mathrm{~h}$ is a feature of the experiments using the KF CP only. In this subsection we explore the characteristics of the KF and GF CP schemes that contribute to the differences in the convective tendencies.

Comparison of the average mixing ratio tendencies produced by the CPs (Figs. 13a,b) for the Thom-KF and Thom-GF experiments shows that the magnitudes of the moisture tendencies in the KF scheme are more than an order of magnitude larger than in the GF scheme. The $q_{r}$ tendency from the CP in the Thom-KF experiment (Fig. 13a) is approximately equal in magnitude and opposite in sign to the total $q_{r}$ tendency from the microphysics for this experiment, as shown in Fig. 10c, suggesting that in this case the MP acts mainly to remove rainwater produced by the KF scheme. Water vapor is converted to both cloud water and rain. In contrast, in the Thom-GF experiment (Fig. 13b), there appears to be more vertical transport of moisture, with water vapor moved from lower levels to higher levels, and condensed to form cloud water only.

Consistent with the moisture tendencies, the average heating from convection in the Thom-KF run (Fig. 13c) is much larger than in the Thom-GF experiment (Fig. 13d). Contributions from microphysics and convection are nearly equivalent in the Thom-KF run, and have similar profiles, with a sharp peak at low levels, corresponding to the level with the maximum conversion of water vapor to rain. When the GF scheme is used, the temperature change due to microphysics is much larger than that due to convection. The convective and microphysical tendencies in the Thom-KF experiment again suggest that the processes simulated by the $\mathrm{CP}$ and MP schemes are similar, whereas in the Thom-GF experiment, the CP and MP schemes appear to be parameterizing different mechanisms for cloud and rain production. A comparison of the Morr-KF and Morr-GF experiments gives nearly identical results (not shown). 

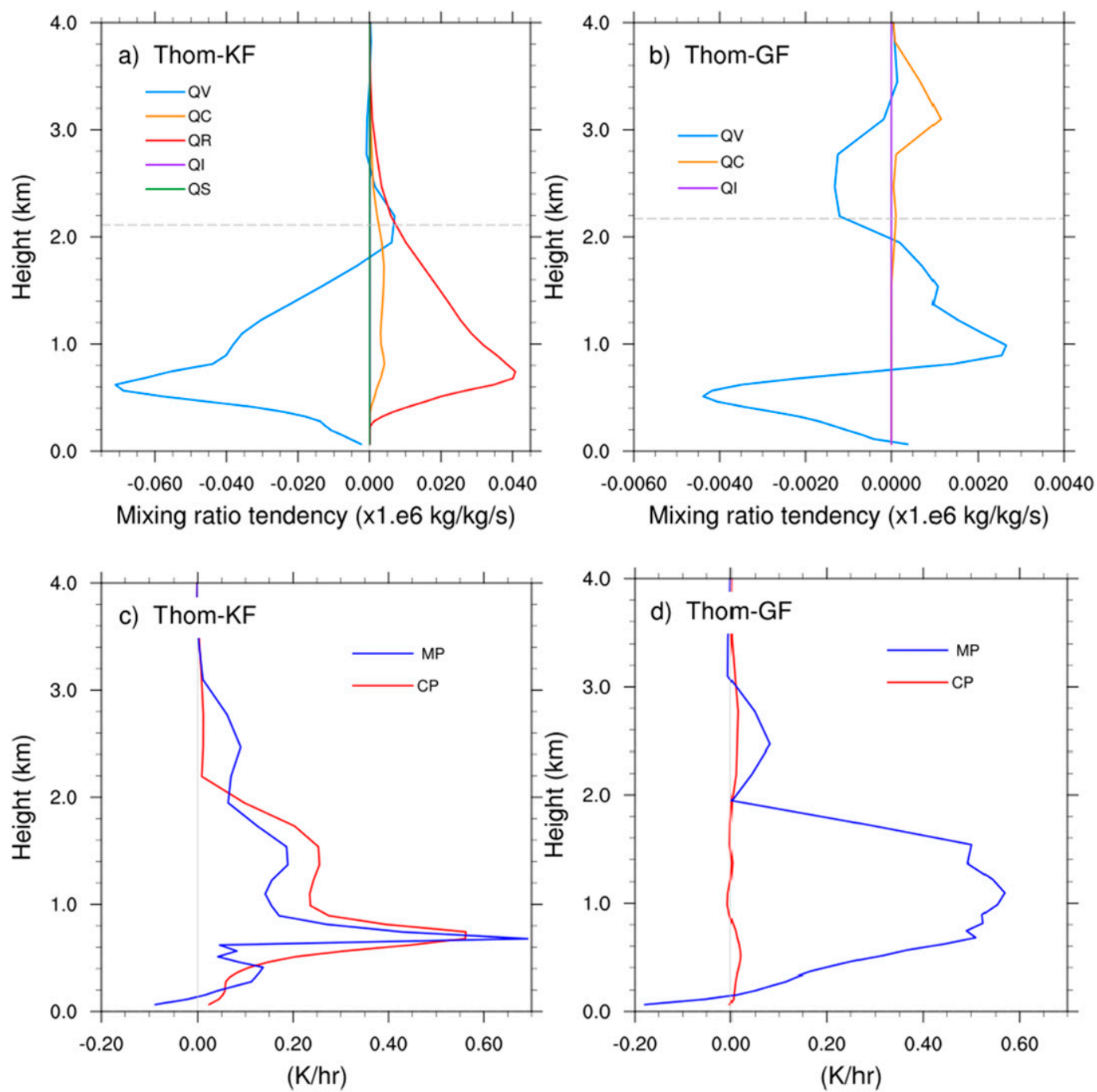

FIG. 13. (a),(b) Vertical profiles of the averaged mixing ratio tendencies produced by the convective parameterization. (c),(d) Vertical profiles of the averaged potential temperature tendencies from the convective parameterization (CP) and the microphysics parameterization (MP) are compared. Results from the Thom-KF experiment are on the left, and from the Thom-GF experiment are on the right. Time averaging was from forecast hour 1 to 9 . Spatial averaging was over box B. Note that the scales on the horizontal axes differ.

There are many differences between the KF and GF convective parameterizations in terms of activation, assumed cloud properties, and impact on the environmental air through entrainment and detrainment, all of which may affect the hydrometeor production. A discussion of all these differences is beyond the scope of this paper; however, two features are important in understanding the difference in results: 1) the generation of rainwater, and 2) the impact of "scale awareness."

The KF scheme by default includes both deep and shallow convection. The shallow component is activated when the convective updraft is shallower than the specified minimum cloud depth, but all other criteria for deep convection are met (Kain 2004). Although shallow convection is commonly defined as nonprecipitating, the $\mathrm{KF}$ algorithm allows precipitation from any cloud deeper than about $50 \mathrm{hPa}$. In fact, in the $\mathrm{KF} \mathrm{CP}$, when the shallow scheme is activated, there is (by default, in WRF) direct feedback of precipitating hydrometeors $\left(q_{r}\right.$ and $q_{s}$ ) to the resolved scales at the levels at which it is formed (Kain 2004). This means that the CP is generating not only cloud hydrometeors, but also rain and snow. This production of $q_{r}$ and $q_{s}$ typically occurs only when shallow convection is active. While this feedback could be considered a tunable parameter, the default value in WRF is 1 (100\% feedback). An experiment 
a) Reflectivity (dBZ)

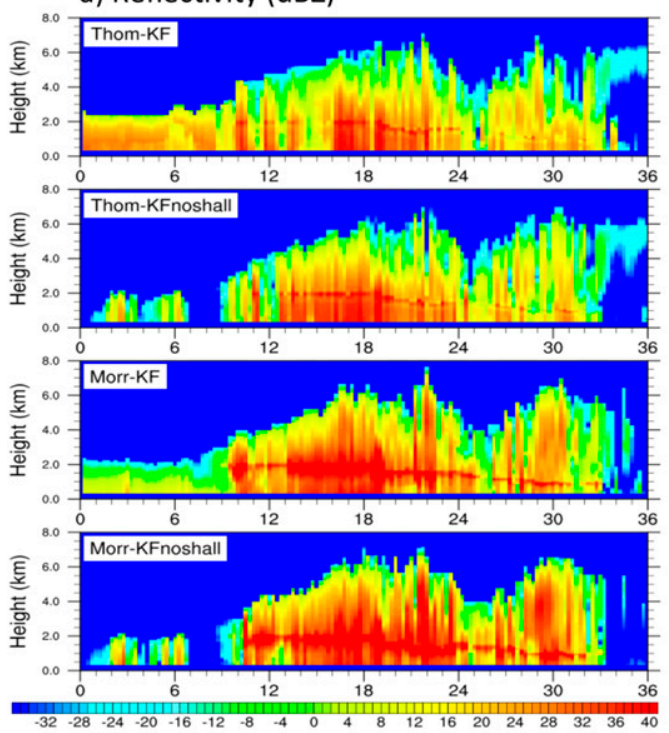

c) Rain Number Concentration $\left(\mathrm{kg}^{-1}\right)$
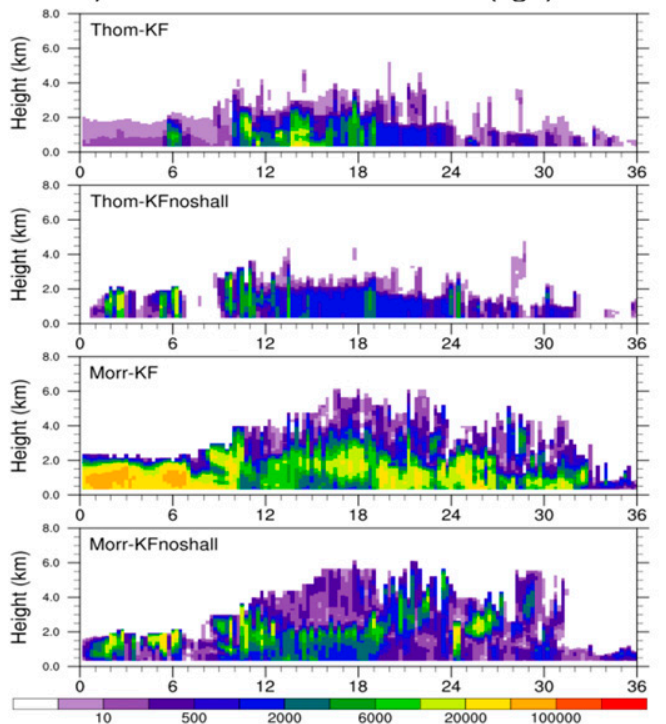

b) Rain Mixing Ratio $(\mathrm{g} / \mathrm{kg})$
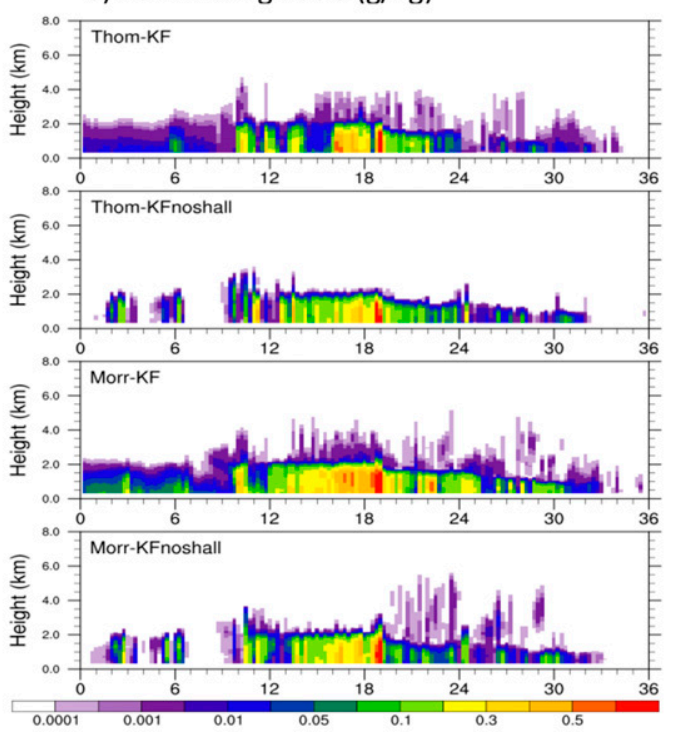

d) Diameter $(\mathrm{mm})$
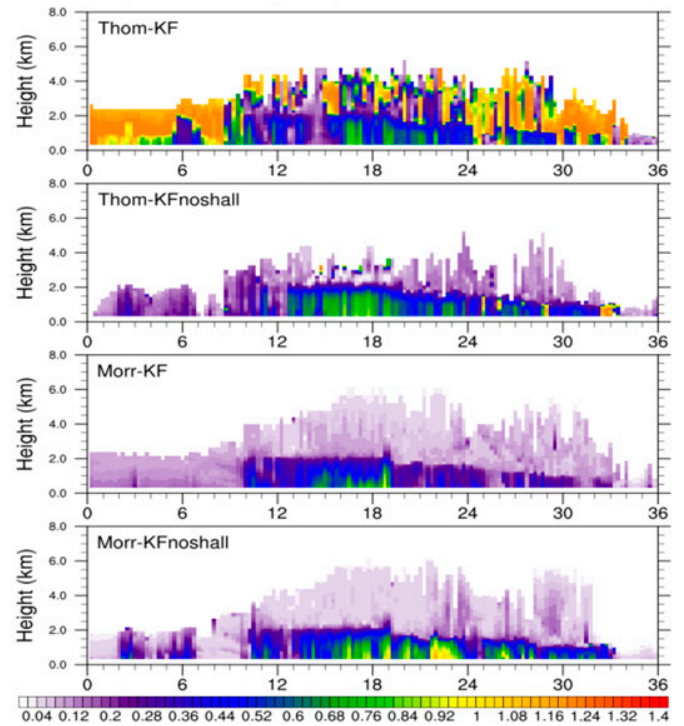

FIG. 14. Time-height series as in Figs. 4-7, showing simulated (a) reflectivity, (b) rain mixing ratio, (c) rain number concentration, and (d) mean raindrop diameter for the Thom-KF, Thom-KFnoshall, Morr-KF, and MorrKFnoshall experiments (listed from top to bottom).

with shallow convection on but this feedback off (not shown) led to substantially decreased clouds and precipitation. While the GF scheme was also implemented with both deep and shallow components, in terms of feedback of detrained hydrometeors to the environment, the GF scheme computes only convective tendencies for cloud water and ice mixing ratios. This difference in predicted variables is likely the primary reason for the different microphysical response to these convective parameterizations seen in this study.
To test the impact of the shallow convection (and its associated feedback of $q_{r}$ and $q_{s}$ ) in the KF scheme, an additional experiment was performed. The ThomKFnoshall experiment is identical to the Thom-KF run, except that shallow convection is turned off in the $\mathrm{KF}$ scheme. Figure 14 displays some results from this experiment, along with the corresponding results from the standard Thom-KF run, for comparison. The timeheight series of reflectivity for this experiment (Fig. 14a, top panel) shows much better agreement with the 

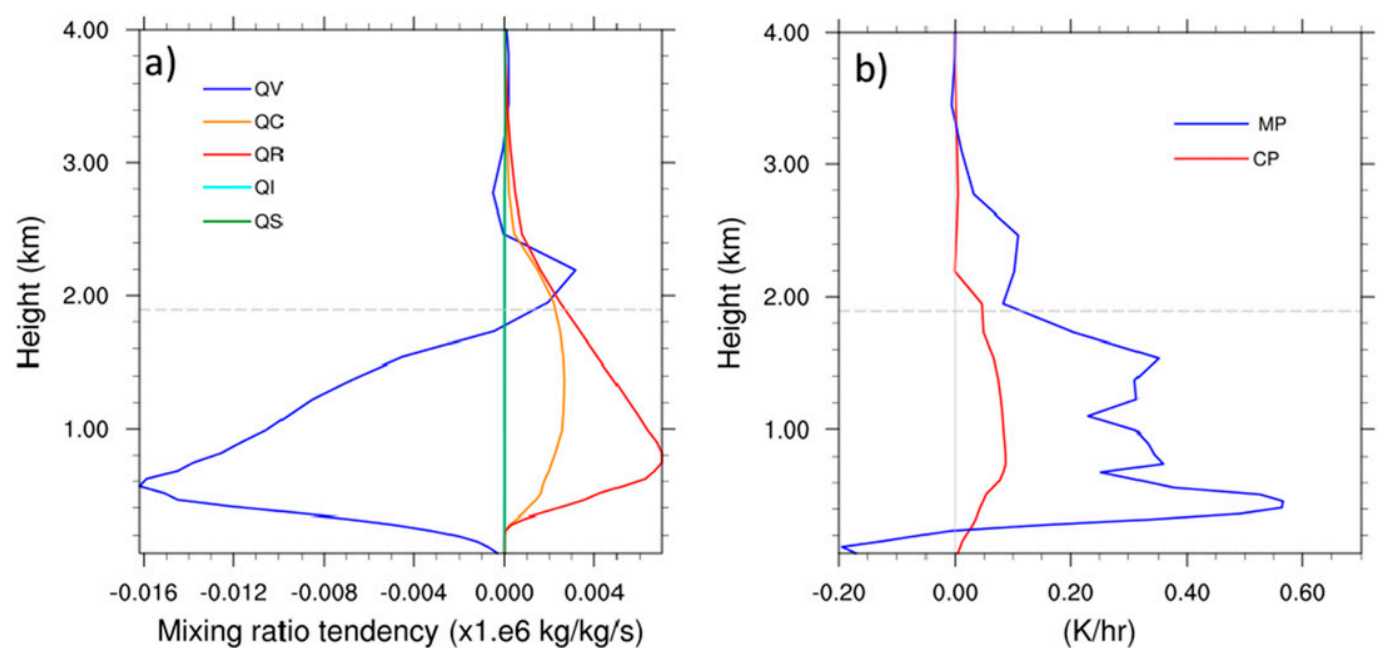

FIG. 15. Vertical profiles of the (a) averaged mixing ratio tendencies produced by the convective parameterization and (b) averaged potential temperature tendencies from the convective parameterization (CP) and the microphysics parameterization (MP) for the Thom-MSKF experiment. Time averaging was from forecast hour 1 to 9. Spatial averaging was over box B.

observed (Fig. 3). Without the modification of rain mixing ratios at low levels by the shallow convection, the high reflectivity, large drop diameters, and very low number concentrations that were present in the Thom$\mathrm{KF}$ experiment are gone, and the $q_{r}$ values are more similar to the other experiments. When the same experiment was repeated with the Morrison MP (the Morr-KFnoshall experiment, Fig. 14, bottom panels), the reflectivity during the first $9 \mathrm{~h}$ was similarly decreased to values more consistent with the observations, and number concentrations throughout the simulation are diminished, compared to the Morr-KF run. The decrease in $N_{r}$ for this experiment is expected, based on the assumptions made in the Morrison scheme for the convective tendencies, as discussed in section $4 \mathrm{~d}$. These results strongly suggest that the detrainment of $q_{r}$ by the shallow component of the KF convective parameterization, without a corresponding change to $N_{r}$, greatly contributed to the inconsistency between $q_{r}$ and $N_{r}$ that led to unrealistic diagnosed reflectivities and drop sizes.

Another important difference between the CPs is that the GF scheme is scale aware (following Arakawa et al. 2011) (i.e., it is dependent upon grid resolution and designed to be less active at high resolution when more cloud processes can be resolved). Heating and drying rates decrease as resolution increases, and when the air is saturated in the presence of upward vertical motion, the scheme is turned off completely (Grell and Freitas 2014). At a resolution of $4 \mathrm{~km}$, precipitation processes due to large-scale uplift may be resolved, causing the $\mathrm{CP}$ to be inactive and allowing these processes to be simulated through the microphysics.
Recently, a scale-aware version of the Kain-Fritsch CP was developed (Zheng et al. 2016), and included in newer versions of the WRF Model (starting with v3.7). To test the impact of scale dependence, this scheme [known as the multiscale Kain-Fritsch scheme (MSKF)] was implemented in WRFv3.6 and run, together with the Thompson MP (Experiment Thom-MSKF). Comparison of the convective heating and moistening tendencies from the Thom-MSKF experiment (Fig. 15) to those from the Thom-KF experiment (Figs. 13a,c), shows that the use of the MSKF scheme did result in a large decrease in magnitude. In addition, the heating contribution from the microphysics increased, becoming significantly larger than the convective contribution. The general pattern of the profiles for the moisture species is similar, however, suggesting that the key physical processes are largely unchanged but the magnitudes are diminished when the multiscale KF scheme is employed. The net $q_{r}$ tendency (not shown) is still almost entirely negative, indicating that the production of $q_{r}$ by convection continues to dominate the microphysical response, although much less so than in the Thom-KF run.

\section{h. Evaluation when convection is more active}

After hour 9, the convective rain rate increased, and was about equal to (in the GF experiments) or greater than (in the KF experiments) the rain rate from resolved processes until about forecast hours $15-16$, when the convective activity decreased sharply and the nonconvective rain rate strongly increased. If the coupling of these CP and MP schemes leads to a persistent 
inconsistency, it should be evident during the 10-15-h time period, when both CP schemes are more active.

Looking back at the 10-15-h period in Fig. 4, the experiments using a CP show mostly weaker reflectivity compared to the NoCP runs during this time. The MorrGF run in particular displays a relatively weak reflectivity signal below the bright band at hours 11-15, with stronger reflectivity above, a physically unrealistic signature. The corresponding number concentrations (Fig. 6) in this experiment are about an order of magnitude larger than in the NoCP run, while $q_{r}$ values (Fig. 5) are smaller. Vertical profiles of temporal and spatial averages of $q_{r}, N_{r}$, and mean drop diameter for the more convective period (Fig. 16) indicate that for both MP schemes, the use of a CP led to a decrease in low-level $q_{r}$, similar to the earlier time period. With the Morrison scheme, in which number concentrations are increased based on the $\mathrm{CP}$ mixing ratio tendencies, both CPs tend to reduce the drop diameter relative to the NoCP run at low levels, by increasing $N_{r}$ while reducing $q_{r}$. From Eq. (1), both changes tend to decrease the reflectivity. When the GF scheme is used, the drop size is generally reduced compared to the NoCP runs for both microphysics schemes. The Thom-KF experiment is the clear outlier in terms of drop diameter, with drop sizes larger than the other experiments at all levels and increasing with height. Typically, rain droplets should be smaller at higher elevations and grow in size through collision and coalescence as they fall through saturated air. Quantities of both $q_{r}$ and $N_{r}$ are very small above about $2.2 \mathrm{~km}$ in this experiment, however. While the direct feedback of $q_{r}$ in the shallow convection component of the KF scheme has been shown to be a major contributor to the $q_{r} / N_{r}$ inconsistency that led to unrealistic reflectivity and DSDs in this case, the problem is not restricted to the KF scheme or to shallow convection regimes.

\section{Discussion and summary}

In this study, we have explored the interaction of two convective parameterization schemes with two doublemoment microphysics schemes. By comparing the derived reflectivity patterns, we have identified an inconsistency that can occur when a two-moment microphysics parameterization is used with a one-moment subgrid cloud parameterization scheme, and explored the sensitivity of the WRF Model to the size distribution assumptions applied to the convection-produced component of the number concentration tendencies.

The degree of inconsistency varied substantially with the choice of convective parameterization, and the type and quantity of detrained hydrometeors produced by
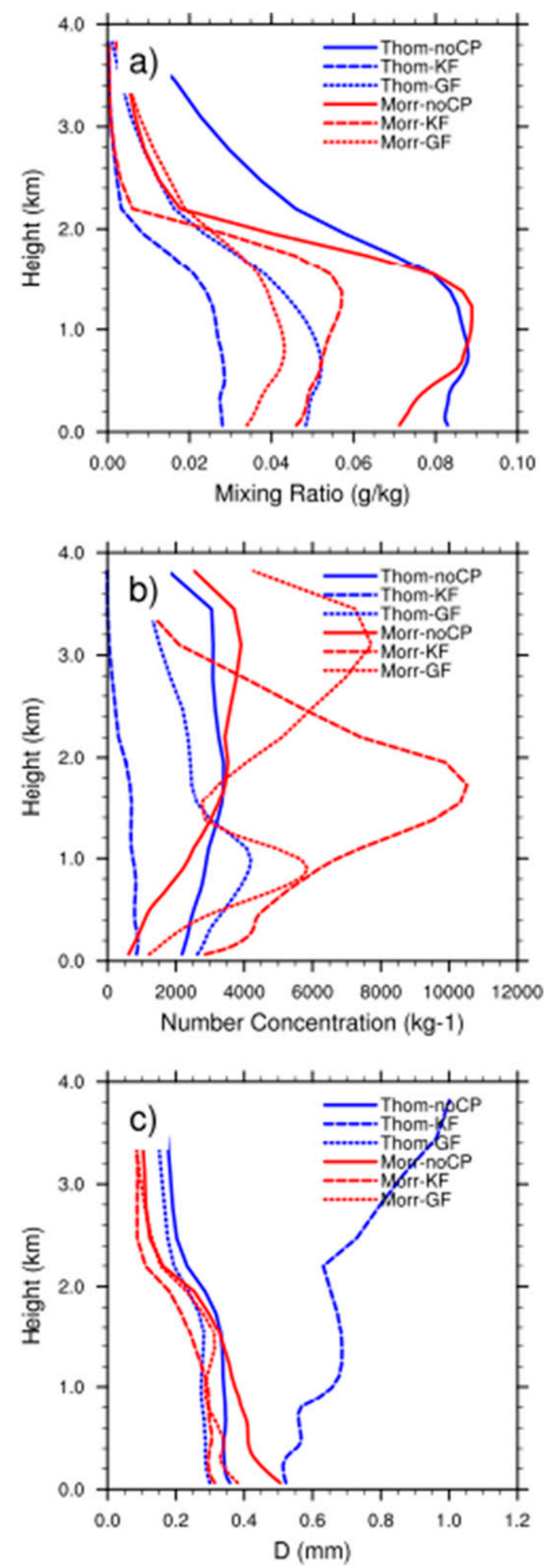

FIG. 16. Vertical profiles of (a) rain mixing ratio, (b) rain number concentration, and (c) mean raindrop diameter for the six experiments, averaged in time for hours 10-15, and in space over box B. 
the CP scheme. For this case, the GF scheme produced only cloud condensate particles $\left(q_{c}, q_{i}\right)$, and a smaller quantity of hydrometeors, and was therefore less problematic, in terms of reflectivity, than the KF scheme, which generated more convective precipitation and both cloud and precipitating hydrometeors. Species such as rain and snow are likely to have larger mass than the cloud particles, and may therefore result in a greater inconsistency in sizedependent number concentration between the $\mathrm{CP}$ and $\mathrm{MP}$ schemes. In particular, the Kain-Fritsch cumulus parameterization allowed direct feedback of rain $\left(q_{r}\right)$ at the level where it was formed, leading to a substantial change in the raindrop size distribution, since there is no information on $N_{r}$ in the convective parameterization to correspond to the $q_{r}$ change. When used with the Thompson scheme, the effect was to produce a small number of extremely large rain drops. When used with the Morrison scheme, which includes a term to estimate the number tendency due to convection, a very large number of tiny drops were produced. Modification to the assumed particle drop size leads to modified precipitation rate and spatial patterns, as well as changes in the vertical distributions of the mixing ratios and number concentrations. It was also noted that the detrained rainwater from the KF scheme leads to a microphysical response that consists primarily of simply removing excess $q_{r}$ produced by convective processes, while there is no detrained rainwater from the GF scheme.

In general, the results indicate that the application of a multimoment microphysics scheme with a convective parameterization that does not have the same level of complexity, in terms of prognostic species, should be approached with caution. While a multimoment microphysics scheme is intended to improve the representation of the hydrometeor size distribution, if applied with a convection parameterization that computes tendencies for only the mass mixing ratio, the prediction of the DSD can actually be degraded. To account for the impact of convection, assumptions can be made about the characteristics of the detrained hydrometeors. The precipitation fields, as well as the mass mixing ratios, number concentration, diagnosed reflectivity, and hydrometeor fall speeds were shown to be sensitive to these assumptions. While the results, in terms of reflectivity, may be improved by such assumptions, this approach is a compromise. The advantage of such a technique is that it allows flexibility in the choice of convection and microphysical parameterization combinations, an important feature in a research model such as WRF. For consistent treatment of two hydrometeor moments, however, a better approach would be to include the same microphysical assumptions in both the MP and the CP schemes.

While this study has focused on mass/number inconsistency in rainwater because it can be identified through reflectivity patterns, a similar inconsistency may exist for cloud water and ice, because of mass detrainment from a convective parameterization, if the species is multimoment in the MP but not in the $\mathrm{CP}$ scheme. The resulting changes in cloud particle characteristics may lead to changes in radiation interactions as well as in precipitation production processes. For example, the equations for the calculation of autoconversion, accretion, and nucleation all include the number concentration of cloud water droplets. Studies by Lohmann (2008) and Song and Zhang (2011) have shown improvements in the simulation of clouds and their radiative properties within climate models when two-moment microphysical processes are explicitly included in the convective parameterization. Zhang and Song (2016) provide an interesting summary of the work in this area. Drawbacks of this method, however, include the increase in computations and restrictions on the possible combinations of $\mathrm{CP}$ and MP schemes.

A current trend in microphysical parameterization schemes is toward increasing complexity, including the prediction of number concentrations in addition to the traditional mass variables such as hydrometeor mixing ratios. Budget analyses in this study indicated that even when no CP is used, the parameterized microphysical processes may over- or underestimate the number concentrations. While the prediction of a second moment can provide beneficial information, there is still a high degree of uncertainty about the accuracy of the calculations, especially if a subgrid cloud scheme is also required. A recent review article by Fan et al. (2016) identifies the need to improve understanding of the dynamical interaction between hydrometeor size distribution, conversions among different types of hydrometeors, and fall speed as a key to reducing uncertainties and improving understanding of aerosol-cloud interactions. Such advancements in understanding are essential for model improvement.

Acknowledgments. The authors thank two anonymous reviewers for their valuable comments that helped improve the presentation of this paper. The authors also acknowledge the use of the NCAR Command Language (NCL) in the analysis of the WRF Model output and the preparation of figures. This work was supported by NOAA USWRP-HMT Award NA15OAR4590160.

\section{REFERENCES}

Albrecht, B. A., 1989: Aerosols, cloud microphysics, and fractional cloudiness. Science, 245, 1227-1230, https://doi.org/10.1126/ science.245.4923.1227.

Arakawa, A., 2004: The cumulus parameterization problem: Past, present, and future. J. Climate, 17, 2493-2525, https://doi.org/ 10.1175/1520-0442(2004)017<2493:RATCPP>2.0.CO;2. 
— , and C.-M. Wu, 2013: A unified representation of deep moist convection in numerical modeling of the atmosphere. Part I. J. Atmos. Sci., 70, 1977-1992, https://doi.org/10.1175/JAS-D-12-0330.1.

_- J.-H. Jung, and C.-M. Wu, 2011: Toward unification of the multiscale modeling of the atmosphere. Atmos. Chem. Phys., 11, 3731-3742, https://doi.org/10.5194/acp-11-3731-2011.

Bao, J.-W., S. A. Michelson, and E. D. Grell, 2016: Pathways to the production of precipitating hydrometeors and tropical cyclone development. Mon. Wea. Rev., 144, 2395-2420, https://doi.org/ 10.1175/MWR-D-15-0363.1.

Cohard, J.-M., and J.-P. Pinty, 2000: A comprehensive twomoment warm microphysical bulk scheme. I: Description and tests. Quart. J. Roy. Meteor. Soc., 126, 1815-1842, https:// doi.org/10.1256/smsqj.56613.

Dawson, D. T., II, M. Xue, J. A. Milbrandt, and M. K. Yau, 2010: Comparison of evaporation and cold pool development between single-moment and multimoment bulk microphysics schemes in idealized simulations of tornadic thunderstorms. Mon. Wea. Rev., 138, 1152-1171, https://doi.org/10.1175/ 2009MWR2956.1.

Dudhia, J., 1989: Numerical study of convection observed during the winter monsoon experiment using a mesoscale twodimensional model. J. Atmos. Sci., 46, 3077-3107, https:// doi.org/10.1175/1520-0469(1989)046<3077:NSOCOD>2.0.CO;2.

Emanuel, K. A., 1994: Atmospheric Convection. Oxford University Press, $580 \mathrm{pp}$.

— , and D. J. Raymond, 1993: The Representation of Cumulus Convection in Numerical Models of the Atmosphere. Meteor. Monogr., No. 46, Amer. Meteor. Soc., 246 pp.

Fan, J., Y. Wang, D. Rosenfeld, and X. Liu, 2016: Review of aerosol-cloud interactions: Mechanisms, significance, and challenges. J. Atmos. Sci., 73, 4221-4252, https://doi.org/ 10.1175/JAS-D-16-0037.1.

Ferrier, B. S., 1994: A double-moment multiple-phase four-class bulk ice scheme. Part I: Description. J. Atmos. Sci., 51, 249-280, https:// doi.org/10.1175/1520-0469(1994)051<0249:ADMMPF>2.0.CO;2.

Frank, W. M., 1983: The cumulus parameterization problem. Mon. Wea. Rev., 111, 1859-1871, https://doi.org/10.1175/1520-0493 (1983) $111<1859$ :TCPP $>2.0$. CO;2.

Gerard, L., 2015: Bulk mass-flux perturbation formulation for a unified approach of deep convection at high resolution. Mon. Wea. Rev., 143, 4038-4063, https://doi.org/10.1175/MWR-D15-0030.1.

Grell, G. A., and S. R. Freitas, 2014: A scale and aerosol aware stochastic convective parameterization for weather and air quality modeling. Atmos. Chem. Phys., 14, 5233-5250, https:// doi.org/10.5194/acp-14-5233-2014.

_, Y.-H. Kuo, and R. Pasch, 1991: Semi-prognostic tests of cumulus parameterization schemes in the middle latitudes. Mon. Wea. Rev., 119, 5-31, https://doi.org/10.1175/1520-0493(1991) $119<0005:$ STOCPS $>2.0 . \mathrm{CO} ; 2$.

IPCC, 2007: Climate Change 2007: The Physical Science Basis. Cambridge University Press, 996 pp.

Janjić, Z. I., 1994: The step-mountain eta coordinate model: Further developments of the convection, viscous sublayer, and turbulence closure schemes. Mon. Wea. Rev., 122, 927-945, https://doi.org/ 10.1175/1520-0493(1994)122<0927:TSMECM>2.0.CO;2.

Kain, J. S., 2004: The Kain-Fritsch convective parameterization: An update. J. Appl. Meteor., 43, 170-181, https://doi.org/ 10.1175/1520-0450(2004)043<0170:TKCPAU>2.0.CO;2.

Kaufman, Y. J., and I. Koren, 2006: Smoke and pollution aerosol effect of cloud cover. Science, 313, 655-658, https://doi.org/ 10.1126/science.1126232.
Kingsmill, D. E., P. J. Neiman, F. M. Ralph, and A. B. White, 2006: Synoptic and topographic variability of northern California precipitation characteristics in landfalling winter storms observed during CALJET. Mon. Wea. Rev., 134, 2072-2094, https://doi.org/10.1175/MWR3166.1.

,-- B. J. Moore, M. Hughes, S. E. Yuter, and F. M. Ralph, 2013: Kinematic and thermodynamic structures of Sierra barrier jets and overrunning atmospheric rivers during a landfalling winter storm in northern California. Mon. Wea. Rev., 141, 2015-2036, https://doi.org/10.1175/MWR-D-12-00277.1.

$\longrightarrow,-\ldots$, and A. B. White, 2016: Microphysics-regime impacts on the relationship between orographic rain and orographic forcing in the coastal mountains of northern California. J. Hydrometeor., 17, 2905-2922, https://doi.org/10.1175/ JHM-D-16-0103.1.

Klein, S. A., and Coauthors, 2009: Intercomparison of model simulations of mixed-phase clouds observed during the ARM Mixed-Phase Arctic Cloud Experiment. I: Single-layer cloud. Quart. J. Roy. Meteor. Soc., 135, 979-1002, https://doi.org/ 10.1002/qj.416.

Lim, K.-S. S., and S.-Y. Hong, 2010: Development of an effective double-moment cloud microphysics scheme with prognostic cloud condensation nuclei (CCN) for weather and climate models. Mon. Wea. Rev., 138, 1587-1612, https://doi.org/ 10.1175/2009MWR2968.1.

Lohmann, U., 2008: Global anthropogenic aerosol effects on convective clouds in ECHAM5-HAM. Atmos. Chem. Phys., 8, 2115-2131, https://doi.org/10.5194/acp-8-2115-2008.

— view. Atmos. Chem. Phys., 5, 715-737, https://doi.org/10.5194/ acp-5-715-2005.

Marshall, J. S., and W. McK. Palmer, 1948: The distribution of raindrops with size. J. Meteor., 5, 165-166, https://doi.org/ 10.1175/1520-0469(1948)005<0165:TDORWS > 2.0.CO;2.

Martner, B. E., S. E. Yuter, A. B. White, S. Y. Matrosov, D. E. Kingsmill, and F. M. Ralph, 2008: Raindrop size distributions and rain characteristics in California coastal rainfall for periods with and without a radar bright band. J. Hydrometeor., 9, 408-425, https://doi.org/10.1175/2007JHM924.1.

Milbrandt, J. A., and M. K. Yau, 2005: A multimoment bulk microphysics parameterization. Part I: Analysis of the role of the spectral shape parameter. J. Atmos. Sci., 62, 3051-3064, https://doi.org/10.1175/JAS3534.1.

— terization. Part III: Control simulation of a hailstorm. J. Atmos. Sci., 63, 3114-3136, https://doi.org/10.1175/ JAS3816.1.

Mlawer, E. J., S. J. Taubman, P. D. Brown, and M. J. Iacono, 1997: Radiative transfer for inhomogeneous atmospheres: RRTM, a validated correlated-k model for the longwave. J. Geophys. Res., 102, 16 663-16 682, https://doi.org/10.1029/97JD00237.

Morrison, H., J. A. Curry, and V. I. Khvorostyanov, 2005: A new double-moment microphysics parameterization for application in cloud and climate models. Part I: Description. J. Atmos. Sci., 62, 1665-1677, https://doi.org/10.1175/JAS3446.1.

—, G. Thompson, and V. Tatarskii, 2009: Impact of cloud microphysics on the development of trailing stratiform precipitation in a simulated squall line: Comparison of one- and two-moment schemes. Mon. Wea. Rev., 137, 991-1007, https:// doi.org/10.1175/2008MWR2556.1.

Neiman, P. J., B. E. Martner, A. B. White, G. A. Wick, F. M. Ralph, and D. E. Kingsmill, 2005: Wintertime nonbrightband rain in California and Oregon during CALJET and PACJET: Geographic, 
interannual, and synoptic variability. Mon. Wea. Rev., 133, 1199-1223, https://doi.org/10.1175/MWR2919.1.

Pan, Y., M. Xue, and G. Ge, 2016: Incorporating diagnosed intercept parameters and the graupel category within the ARPS cloud analysis system for the initialization of double-moment microphysics: Testing with a squall line over South China. Mon. Wea. Rev., 144, 371-392, https://doi.org/10.1175/ MWR-D-15-0008.1.

Ralph, F. M., and Coauthors, 2005: Improving short-term (0-48 h) cool-season quantitative precipitation forecasting: Recommendations from a USWRP Workshop. Bull. Amer. Meteor. Soc., 86, 1619-1632, https://doi.org/10.1175/BAMS-86-11-1619.

— beds linking research and forecasting operations. Bull. Amer. Meteor. Soc., 94, 1187-1211, https://doi.org/10.1175/BAMS-D12-00080.1.

Reisner, J., R. M. Rasmussen, and R. T. Bruintjes, 1998: Explicit forecasting of supercooled liquid water in winter storms using the MM5 mesoscale model. Quart. J. Roy. Meteor. Soc., 124, 1071-1107, https://doi.org/10.1002/qj.49712454804.

Seifert, A., and K. D. Beheng, 2006: A two-moment cloud microphysics parameterization for mixed-phase clouds. Part 1: Model description. Meteor. Atmos. Phys., 92, 45-66, https:// doi.org/10.1007/s00703-005-0112-4.

Skamarock, W. C., and Coauthors, 2008: A description of the Advanced Research WRF version 3. NCAR Tech. Note NCAR/TN-475+STR, 113 pp., http://dx.doi.org/10.5065/ D68S4MVH.

Song, X., and G. J. Zhang, 2011: Microphysics parameterization for convective clouds in a global climate model: Description and single-column model tests. J. Geophys. Res., 116, D02201, https://doi.org/10.1029/2010JD014833.

Tewari, M., and Coauthors, 2004: Implementation and verification of the unified Noah land surface model in the WRF model. 20th Conf. on Weather Analysis and Forecasting/16th Conf. on Numerical Weather Prediction, Seattle, WA, Amer. Meteor. Soc., 14.2a, https://ams.confex.com/ams/84Annual/techprogram/ paper_69061.htm.

Thompson, G., R. M. Rasmussen, and K. Manning, 2004: Explicit forecasts of winter precipitation using an improved bulk microphysics scheme. Part I: Description and sensitivity analysis.
Mon. Wea. Rev., 132, 519-542, https://doi.org/10.1175/ 1520-0493(2004)132<0519:EFOWPU>2.0.CO;2.

—, P. R. Field, R. M. Rasmussen, and W. D. Hall, 2008: Explicit forecasts of winter precipitation using an improved bulk microphysics scheme. Part II: Implementation of a new snow parameterization. Mon. Wea. Rev., 136, 5095-5115, https:// doi.org/10.1175/2008MWR2387.1.

Twomey, S., 1977: Influence of pollution on shortwave albedo of clouds. J. Atmos. Sci., 34, 1149-1152, https://doi.org/10.1175/ 1520-0469(1977)034<1149:TIOPOT>2.0.CO;2.

White, A. B., J. R. Jordan, B. E. Martner, F. M. Ralph, and B. W. Bartram, 2000: Extending the dynamic range of an S-band radar for cloud and precipitation studies. J. Atmos. Oceanic Technol., 17, 1226-1234, https://doi.org/10.1175/1520-0426(2000) 017<1226:ETDROA > 2.0.CO;2.

_ P. J. Neiman, F. M. Ralph, D. E. Kingsmill, and P. O. G. Persson, 2003: Coastal orographic rainfall processes observed by radar during the California Land-Falling Jets Experiment. J. Hydrometeor., 4, 264-282, https://doi.org/10.1175/15257541(2003)4<264:CORPOB >2.0.CO;2.

,-- J. M. Creamean, T. Coleman, F. M. Ralph, and K. A. Prather, 2015: The impacts of California's San Francisco Bay area gap on precipitation observed in the Sierra Nevada during HMT and CalWater. J. Hydrometeor., 16, 1048-1069, https://doi.org/10.1175/JHM-D-14-0160.1.

Zhang, G. J., and X. Song, 2016: Parameterization of microphysical processes in convective clouds in global climate models. Multiscale Convection-Coupled Systems in the Tropics: A Tribute to Dr. Michio Yanai, Meteor. Monogr., No. 56, Amer. Meteor. Soc., 12.1-12.18, https://doi.org/10.1175/AMSMONOGRAPHSD-15-0015.1.

Zhang, G., M. Xue, Q. Cao, and D. Dawson, 2008: Diagnosing the intercept parameter for exponential raindrop size distribution based on video disdrometer observations: Model development. J. Appl. Meteor. Climatol., 47, 2983-2992, https:// doi.org/10.1175/2008JAMC1876.1.

Zheng, Y., K. Alapaty, J. A. Herwehe, A. D. Del Genio, and D. Niyogi, 2016: Improving high-resolution weather forecasts using the Weather Research and Forecasting (WRF) Model with an updated Kain-Fritsch scheme. Mon. Wea. Rev., 144, 833-860, https://doi.org/10.1175/MWR-D-15-0005.1. 